\title{
Article
}

\section{Leptosporella (Leptosporellaceae fam. nov.) and Linocarpon and Neolinocarpon (Linocarpaceae fam. nov.) are accommodated in Chaetosphaeriales}

\author{
Konta $\mathrm{S}^{1,2}$, Hongsanan $\mathrm{S}^{1}$, Liu $\mathrm{JK}^{3}$, Eungwanichayapant $\mathrm{PD}^{2}$, Jeewon $\mathbf{R}^{4}$, Hyde \\ $\mathrm{KD}^{1}$, Maharachchikumbura $\mathrm{SSN}^{5}$, and Boonmee $\mathrm{S}^{1 *}$ \\ ${ }^{1}$ Center of Excellence in Fungal Research, Mae Fah Luang University, Chiang Rai 57100, Thailand \\ ${ }^{2}$ School of Science, Mae Fah Luang University, Chiang Rai. 57100, Thailand \\ ${ }^{3}$ Guizhou Institute of Biotechnology, Guizhou Academy of Agricultural Sciences, Guiyang, Guizhou 550006, People's \\ Republic of China \\ ${ }^{4}$ Department of Health Sciences, Faculty of Science, University of Mauritius, Reduit 80837, Mauritius \\ ${ }^{5}$ Department of Crop Sciences, College of Agricultural and Marine Sciences, Sultan Qaboos University, P.O. Box 8, \\ 123, Al Khoud, Oman
}

Konta S, Hongsanan S, Eungwanichayapant PD, Liu JK, Jeewon R, Hyde KD, Maharachchikumbura SSN, Boonmee S 2017 - Leptosporella (Leptosporellaceae fam. nov.) and Linocarpon and Neolinocarpon (Linocarpaceae fam. nov.) are accommodated in Chaetosphaeriales. Mycosphere 8(10), 1943-1974, Doi 10.5943/mycosphere/8/10/16

\begin{abstract}
In this paper we introduce the new species Leptosporella arengae and L. cocois, Linocarpon arengae and L. cocois, and Neolinocarpon arengae and N. rachidis from palms in Thailand, based on morphology and combined analyses of ITS and LSU sequence data. The phylogenetic positions all these new taxa are well-supported within the order Chaetosphaeriales (subclass Sordariomycetidae), but in distinct lineages. Therefore, a new family, Leptosporellaceae is introduced to accommodate species of Leptosporella, while Linocarpaceae, which constitutes a well-supported monophyletic clade is also introduced to accommodate Linocarpon and Neolinocarpon species. Both families are characterised by specific traits, such as the shape of ascomata and filiform, hyaline ascospores, which may be pale brown-yellowish in mass, that demarcate it from other families.
\end{abstract}

Key words -2 new families -6 new species - filiform ascospores - palm fungi - Phylogeny Taxonomy - Sordariomycetes

\section{Introduction}

We have studied the genera of ascomycetes on palms since Hyde (1988). In most previous studies, taxa were introduced based solely on morphology (such as ascomata, asci and ascospores) and referred to different taxonomic ranks within the Ascomycota (Fröhlich \& Hyde 2000, Taylor \& Hyde 2003). This approach was, however, subjective and many taxa were assigned mostly to Ascomycota genera incertae sedis. Given that palms are important hosts with potential novel species, it is essential that these palm micro-fungi are recollected, epitypified where needed, isolated and sequence data obtained so that the palm microfungi can be placed in a natural taxonomic framework (Ariyawansa et al. 2014, Jayasiri et al. 2015). 
Penzig \& Saccardo (1897) introduced Leptosporella Penz. \& Sacc. with L. gregaria Penz. \& Sacc. as the type species. Leptosporella was placed in Sordariomycetidae, genera incertae sedis by Lumbsch \& Huhndorf (2010). The holotype was re-examined and fresh specimens collected and the genus was referred to the Chaetosphaeriales based on phylogenetic analysis of LSU sequence data (Huhndorf \& Miller 2011, Dai et al. 2016). Linocarpon was introduced by Sydow \& Sydow (1917), monographed by Hyde (1992a, 1997) with 23 accepted species. Many researchers have added novel species to this genus and accommodated them in Xylariaceae (Xylariales) (Dulymamode et al. 1998, Hyde \& Alias 1999, Fröhlich \& Hyde 2000, Thongkantha et al. 2003, Cai et al. 2004). Hyde (1992b) introduced Neolinocarpon K.D. Hyde as a novel genus which is typified by N. globosicarpum K.D. Hyde. The genus Neolinocarpon cannot be placed in any family within Xylariales with certainty and thus has been referred as Xylariales genera incertae sedis (Jones et al. 2009a, b, Maharachchikumbura et al. 2015).

Our fungal collections from palms have revealed six new species (Leptosporella arengae, $L$. cocois, Linocarpon arengae, L. cocois, Neolinocarpon arengae, $N$. rachidis) and these are described herein and their placement is supported with DNA sequence analyses. In this paper, we also accommodate Linocarpon and Neolinocarpon in Linocarpaceae fam. nov. and Leptosporella in Leptosporellaceae fam. nov. (Chaetosphaeriales). We list 12 species of Leptosporella, 41 species of Linocarpon, and 10 species of Neolinocarpon, however the known taxa need recollecting with molecular data, to establish their natural placements. Although some species have been transferred to other genera based on their morphological characteristics (Höhnel 1909, Arx \& Olivier 1952, Petrak 1952, Walker 1980, Cribb \& Cribb 1955, Vasilyeva 1993), most species have been introduced using only morphological characteristics, while less than 20 species have sequence data. All genera included in this study are poorly represented with sequence data in GenBank.

\section{Materials \& Methods}

\section{Collection, isolation and identification}

Palm materials were collected from southern and western of Thailand. Specimens were examined with a Motic SMZ 168 series stereomicroscope and photographed with an Axio camera on a Zeiss Discover V8 stereomicroscope. Micromorphological structures were photographed with a Canon 600D camera on a Nikon ECLIPSE 80i microscope and measurement by Image Frame Work program (IFW) version 0.9.7. Photoplates were made with Adobe Photoshop CS5 Extended version 10. Isolations were made from single ascospores following the method of Chomnunti et al. (2014). Colony structures were recorded after seven days and/or until the colony growth nearly filled the Petri-dish when incubated at $25-28^{\circ} \mathrm{C}$ on MEA media. Holotype specimens are deposited in herbarium of Mae Fah Luang University (MFLU) and Herbarium of Kunming Institute of Botany, Chinese Academy of Sciences (HKAS). Living cultures are deposited in Mae Fah Luang University Culture Collection (MFLUCC) and BIOTEC Culture Collection Laboratory (BCC). Facesoffungi and Index Fungorum numbers are registered as outlined in Jayasiri et al. (2015) and Index Fungorum (2017). New species are established based on recommendations of Jeewon \& Hyde (2016).

\section{Fungal DNA extraction and PCR reaction}

Genomic DNA was extracted from fresh mycelium grown on MEA for two weeks using the Biospin Fungus Genomic DNA Extraction Kit (BioFlux $\left.{ }^{\circledR}\right)$. Specific rDNA regions were amplified with different gene primers, i.e. LROR and LR5 to amplify the large subunit rDNA (LSU) (Vilgalys \& Hester 1990), NS1 and NS4 to amplify region of nuclear small subunit rDNA (SSU), ITS5 and ITS4 to amplify the internal transcribed spacers (ITS) (White et al. 1990), RPB2-5F and RPB2-7CR to amplify the RNA polymerase subunit II (RPB2) (Liu et al. 1999, Sung et al. 2007), 
Table 1 Ascomata, hamathecium, asci and ascospore dimensions of species in Leptosporella, Linocarpon and Neolinocarpon.

\begin{tabular}{|c|c|c|c|c|c|c|}
\hline Species name & Ascomata & Hamathecium & Asci & Ascospores & Host/Substrates/Location & References \\
\hline $\begin{array}{l}\text { Leptosporella } \\
\text { ambiens }\end{array}$ & $\begin{array}{l}300-400 \mu \mathrm{m} \text { diameter } \\
\times 450 \mu \mathrm{m} \text { high }\end{array}$ & $2 \mu \mathrm{m}$ & $150 \times 12-15 \mu \mathrm{m}$ & $\begin{array}{l}120 \times 3 \mu \mathrm{m}, \\
\text { parallel, filiform }\end{array}$ & $\begin{array}{l}\text { On stalks of Compositae } \\
\text { vivae (Asteraceae) } \\
\text { Rio de Janeiro, } \\
\text { Brazil }\end{array}$ & Rehm 1901 \\
\hline L. andina & - & - & - & - & $\begin{array}{l}\text { On dead branchlets of a } \\
\text { shrub } \\
\text { Venezuela }\end{array}$ & $\begin{array}{l}\text { Chardón \& Toro } \\
\text { 1934, Spegazzini } \\
1912\end{array}$ \\
\hline $\begin{array}{l}{ }^{*} \text { L. arengae } \\
\text { MFLU 15-0305 }\end{array}$ & $\begin{array}{l}582-928 \mu \mathrm{m} \text { diameter } \\
\times 293-354 \mu \mathrm{m} \text { high }\end{array}$ & $1.5-3 \mu \mathrm{m}$ diameter & $137-190 \times 10-14 \mu \mathrm{m}$ & $\begin{array}{l}108-132 \times 2-3.5 \\
\mu \mathrm{m}, \mathrm{C}-\text { shaped or } \\
\text { sigmoid, ends } \\
\text { rounded, with polar } \\
\text { mucilaginous } \\
\text { appendages }\end{array}$ & $\begin{array}{l}\text { On dead rachis of Arenga } \\
\text { pinnata (Arecaceae) } \\
\text { Thailand }\end{array}$ & In this study \\
\hline${ }^{*}$ L. bambusae & $\begin{array}{l}500-850 \mu \mathrm{m} \text { diameter } \\
\times 200-250 \mu \mathrm{m} \text { high }\end{array}$ & $2-3.5 \mu \mathrm{m}$ diameter & $\begin{array}{l}100-195.5 \times 9-13.5 \\
\mu \mathrm{m}\end{array}$ & $\begin{array}{l}130-175 \times 2-3 \mu \mathrm{m}, \\
2-6 \text {-septate curved, } \\
\text { narrow, acute at } \\
\text { both ends }\end{array}$ & $\begin{array}{l}\text { On dead culms of bamboo } \\
\text { (Poaceae) } \\
\text { Thailand }\end{array}$ & Dai et al. 2016 \\
\hline L. clelandii & - & - & - & - & $\begin{array}{l}\text { On dead branches of } \\
\text { Acacia kempeana } \\
\text { (Fabaceae) } \\
\text { Central Australia }\end{array}$ & Hansford 1957 \\
\hline L. clinopodii & 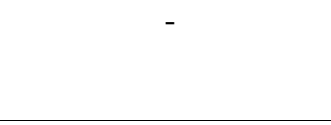 & - & 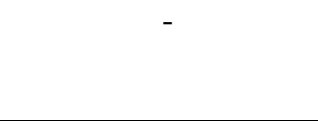 & - & $\begin{array}{l}\text { Clinopodium chinense } \\
\text { (Lamiaceae) } \\
\text { Taiwan }\end{array}$ & Sawada 1943 \\
\hline $\begin{array}{l}\text { *L. cocois } \\
\text { MFLU 15-2349 }\end{array}$ & $\begin{array}{l}705-977 \mu \mathrm{m} \text { diameter } \\
\times 209-298 \mu \mathrm{m} \text { high }\end{array}$ & 3-6 $\mu \mathrm{m}$ diameter & $145-242 \times 8-13 \mu \mathrm{m}$ & $\begin{array}{l}99-156 \times 2.5-4 \mu \mathrm{m}, \\
\text { straight or curved, } \\
\text { rounded at the apex, } \\
\text { pointed at the base }\end{array}$ & $\begin{array}{l}\text { On dead rachis of Cocos } \\
\text { nucifera (Arecaceae) } \\
\text { Thailand }\end{array}$ & In this study \\
\hline L. dicksoniae & - & - & - & - & $\begin{array}{l}\text { Dicksonia squarrosa } \\
\text { (Dicksoniaceae) } \\
\text { Portugal }\end{array}$ & $\begin{array}{l}\text { Sousa da Camara } \\
\& \text { da Luz } 1939\end{array}$ \\
\hline $\begin{array}{l}\#,{ }^{*} L . \text { gregaria (type } \\
\text { species) }\end{array}$ & $\begin{array}{l}800-1,000 \mu \mathrm{m} \\
\text { diameter }\end{array}$ & filiform & $100 \times 9-10 \mu \mathrm{m}$ & $\begin{array}{l}55-70 \times 2.5-3 \mu \mathrm{m} \\
7 \text {-septate }\end{array}$ & $\begin{array}{l}\text { Wood } \\
\text { Tjibodas, Java, Indonesia }\end{array}$ & $\begin{array}{l}\text { Penzig \& } \\
\text { Saccardo1897, } \\
\text { Huhndorf et al. } \\
\text { 2004, Huhndorf \& } \\
\text { Miller 2011 }\end{array}$ \\
\hline
\end{tabular}


Table 1 Continued.

\begin{tabular}{|c|c|c|c|c|c|c|}
\hline Species name & Ascomata & Hamathecium & Asci & Ascospores & Host/Substrates/Location & References \\
\hline L. leucodontis & - & - & - & - & $\begin{array}{l}\text { On dead leaves of } \\
\text { Leucodon sciuroides } \\
\text { (Leucodontaceae) } \\
\text { France }\end{array}$ & Racovitza 1959 \\
\hline L. lignicola & - & - & - & - & $\begin{array}{l}\text { Wood } \\
\text { Venezuela }\end{array}$ & Chardón 1939 \\
\hline L. macrotheca & $350-600 \mu \mathrm{m}$ diameter & $1-1.5$ diameter $\mu \mathrm{m}$ & $\begin{array}{l}179-200 \times 12-15 \\
\mu \mathrm{m}\end{array}$ & $82-110 \times 4-5 \mu \mathrm{m}$ & $\begin{array}{l}\text { Wood } \\
\text { New South Wales }\end{array}$ & Sydow 1938 \\
\hline L. rosae & - & - & - & - & $\begin{array}{l}\text { On dead branches of Rosa } \\
\text { (Rosaceae) } \\
\text { Uttar Pradesh, India }\end{array}$ & $\begin{array}{l}\text { Edward et al. } 1972 \\
\text { (Not validly } \\
\text { published) }\end{array}$ \\
\hline L. sparsa & $300 \mu \mathrm{m}$ diameter & no observed & $90-120 \times 9-12 \mu \mathrm{m}$ & $30-35 \times 3 \mu \mathrm{m}$ & $\begin{array}{l}\text { Wood } \\
\text { Java }\end{array}$ & $\begin{array}{l}\text { Penzig \& Saccardo } \\
1897\end{array}$ \\
\hline Linocarpon alpiniae & $\begin{array}{l}400 \mu \mathrm{m} \text { diameter } \times \\
100 \mu \mathrm{m} \text { high }\end{array}$ & up to $4 \mu \mathrm{m}$ at the base & $81-108 \times 8-11 \mu \mathrm{m}$ & $\begin{array}{l}58-68 \times 2.25-3 \mu \mathrm{m}, \\
\text { lack refringent } \\
\text { septum-like bands, } \\
\text { ends of a rounded } \\
\text { point with a minute } \\
\text { mucilaginous drop }\end{array}$ & $\begin{array}{l}\text { On basal stem of Alpinia } \\
\text { (Zingiberaceae) } \\
\text { Malaysia, Peninsular }\end{array}$ & Hyde 1997 \\
\hline${ }^{*, \$}$ L. angustatum & $\begin{array}{l}800-944 \mu \mathrm{m} \text { diameter } \\
\times 400-448 \mu \mathrm{m} \text { high }\end{array}$ & 2-3 $\mu \mathrm{m}$ diameter & $\begin{array}{l}125-195 \times 12.5-22 \\
\mu \mathrm{m}\end{array}$ & $\begin{array}{l}57.5-87.5 \times 3.5-6 \\
\mu \mathrm{m}, \text { needle-shaped, } \\
\text { narrow, point at the } \\
\text { base, inconspicuous } \\
\text { mucilage }\end{array}$ & $\begin{array}{l}\text { On intertidal petiole of } \\
\text { Nypa fruticans (Arecaceae) } \\
\text { Malaysia, Peninsular }\end{array}$ & $\begin{array}{l}\text { Hyde \& Alias 1999, } \\
\text { Bahl } 2006\end{array}$ \\
\hline L. apiculatum & $\begin{array}{l}400-650 \mu \mathrm{m} \text { diameter } \\
\times 80 \mu \mathrm{m} \text { high }\end{array}$ & up to $4 \mu \mathrm{m}$ at the base & $120-140 \times 9-11 \mu \mathrm{m}$ & $56-64 \times 3.5-4.5 \mu \mathrm{m}$ & $\begin{array}{l}\text { On decaying petiole of } \\
\text { palm in freshwater swamp } \\
\text { (Arecaceae) } \\
\text { Papua New Guinea, Irian } \\
\text { Jaya }\end{array}$ & Hyde 1997 \\
\hline *L. appendiculatum & $\begin{array}{l}330-510 \mu \mathrm{m} \text { diameter } \\
\times 120-180 \mu \mathrm{m} \text { high }\end{array}$ & wide at the base & $\begin{array}{l}110.5-169 \times 7.8-9.8 \\
\mu \mathrm{m}\end{array}$ & $\begin{array}{l}75-120 \times 2.2-3.5 \\
\mu \mathrm{m}, \text { with an } \\
\text { appendage at a polar } \\
\text { swelling with a } \\
\text { flattened end (bell- } \\
\text { shaped) containing } \\
\text { mucilage }\end{array}$ & $\begin{array}{l}\text { On rotten fronds of Nypa } \\
\text { fruticans (Arecaceae) } \\
\text { Brunei }\end{array}$ & $\begin{array}{l}\text { Hyde 1988, 1992, } \\
\text { Huhndorf et al. } \\
\text { 2004, Miller \& } \\
\text { Huhndorf 2005, } \\
\text { Bahl } 2006\end{array}$ \\
\hline
\end{tabular}


Table 1 Continued.

\begin{tabular}{|c|c|c|c|c|c|c|}
\hline Species name & Ascomata & Hamathecium & Asci & Ascospores & Host/Substrates/Location & References \\
\hline L. appendisporum & $\begin{array}{l}320 \mu \mathrm{m} \text { diameter } \times \\
150 \mu \mathrm{m} \text { high }\end{array}$ & $\begin{array}{l}\text { up to } 6.5 \mu \mathrm{m} \text { at the } \\
\text { base }\end{array}$ & $100-150 \times 8-10 \mu \mathrm{m}$ & $\begin{array}{l}60-76 \times 2.75-4 \mu \mathrm{m}, \\
\text { appendages at each } \\
\text { ends containing } \\
\text { mucilage }\end{array}$ & $\begin{array}{l}\text { On dead leaves of } \\
\text { Pandanus in freshwater } \\
\text { swamp (Pandanaceae) } \\
\text { Papua New Guinea, Irian } \\
\text { Jaya }\end{array}$ & Hyde 1997 \\
\hline L. aquaticum & $\begin{array}{l}420-700 \mu \mathrm{m} \text { diameter } \\
\times 300-450 \mu \mathrm{m} \text { high }\end{array}$ & up to $4 \mu \mathrm{m}$ at the base & $\begin{array}{l}180-260 \times 12-14 \\
\mu \mathrm{m}\end{array}$ & $\begin{array}{l}110-160 \times 2.4-2.8 \\
\mu \mathrm{m}, \text { appendages at } \\
\text { each ends, which } \\
\text { grasps a mucilaginous }\end{array}$ & $\begin{array}{l}\text { On rachis of palm } \\
\text { (Arecaceae) } \\
\text { Australia, Queensland }\end{array}$ & Hyde 1997 \\
\hline $\begin{array}{l}\text { *L. arengae } \\
\text { MFLU 15-0306 }\end{array}$ & $\begin{array}{l}878-1,368 \mu \mathrm{m} \\
\text { diameter } \times 125-355 \\
\mu \mathrm{m} \text { high }\end{array}$ & $2-3.5 \mu \mathrm{m}$ diameter & $132-177 \times 9-15 \mu \mathrm{m}$ & $\begin{array}{l}91-102 \times 2-4 \mu \mathrm{m}, \\
\text { ends rounded, with } \\
\text { polar mucilaginous } \\
\text { appendage at apex }\end{array}$ & $\begin{array}{l}\text { On dead rachis of Arenga } \\
\text { pinnata (Arecaceae) } \\
\text { Thailand }\end{array}$ & In this study \\
\hline L. australiense & $\begin{array}{l}520 \mu \mathrm{m} \text { diameter } \times \\
120 \mu \mathrm{m} \text { high }\end{array}$ & $\begin{array}{l}\text { up to } 3 \mu \mathrm{m} \text { diameter } \\
\text { at the base }\end{array}$ & $\begin{array}{l}124-150 \times 8-12 \\
\mu \mathrm{m}\end{array}$ & $\begin{array}{l}92-108 \times 2-2.5 \mu \mathrm{m}, \\
\text { C-shaped or sigmoid, } \\
\text { cream color in mass, } \\
\text { ends round with an } \\
\text { apiculate short } \\
\text { appendage }\end{array}$ & $\begin{array}{l}\text { On rachis of Licuala } \\
\text { ramseyi, Archontophoenix } \\
\text { alexandrae (Arecaceae) } \\
\text { Australia, Queensland }\end{array}$ & $\begin{array}{l}\text { Hyde } 1997, \text { Taylor } \\
\text { \& Hyde } 2003\end{array}$ \\
\hline L. bambusicola & $\begin{array}{l}700-1300 \mu \mathrm{m} \\
\text { diameter } \times 550-780 \\
\mu \mathrm{m} \text { high }\end{array}$ & $\begin{array}{l}\text { up to } 4 \mu \mathrm{m} \text { wide at the } \\
\text { base }\end{array}$ & $\begin{array}{l}155-(175)-190 \times \\
7.5-(9.5)-11 \mu \mathrm{m}\end{array}$ & $\begin{array}{l}107-132.5-170 \times 1.5- \\
1.8-2 \mu \mathrm{m}, \text { rounded at } \\
\text { the apex, the basal end } \\
\text { provided with } 1-3 \\
\text { minute mucilaginous } \\
\text { drops }\end{array}$ & $\begin{array}{l}\text { On stems of bamboo } \\
\text { submerged in river } \\
\text { (Poaceae) } \\
\text { Philippines }\end{array}$ & Cai et al. 2004 \\
\hline L. bipolare & $\begin{array}{l}520-1040 \mu \mathrm{m} \\
\text { diameter } \times 195-325 \\
\mu \mathrm{m} \text { high }\end{array}$ & $\begin{array}{l}9 \mu \mathrm{m} \text { at the base and } 1 \\
\mu \mathrm{m} \text { distally }\end{array}$ & $\begin{array}{l}150-215 \times 7.5-12 \\
\mu \mathrm{m}\end{array}$ & $90-139 \times 2-3 \mu \mathrm{m}$ & $\begin{array}{l}\text { On intertidal fronds of } \\
\text { Nypa fruticans (Arecaceae) } \\
\text { Brunei }\end{array}$ & Hyde $1992 \mathrm{a}$ \\
\hline L. breve & $\begin{array}{l}600 \mu \mathrm{m} \text { diameter } \times \\
130 \mu \mathrm{m} \text { high }\end{array}$ & $\begin{array}{l}\text { up to } 3 \mu \mathrm{m} \text { wide at the } \\
\text { base }\end{array}$ & $\begin{array}{l}104-138 \times 4.5-6 \\
\mu \mathrm{m}\end{array}$ & $\begin{array}{l}34-45 \times 2.2-2.6 \mu \mathrm{m}, \\
2-3 \text {-seriate, with a } \\
\text { collar-like appendage } \\
\text { containing mucilage at } \\
\text { each ends }\end{array}$ & $\begin{array}{l}\text { On dead leaves of } \\
\text { Pandanus (Pandanaceae) } \\
\text { Papua New Guinea, Irian } \\
\text { Jaya }\end{array}$ & Hyde 1997 \\
\hline
\end{tabular}


Table 1 Continued.

\begin{tabular}{|c|c|c|c|c|c|c|}
\hline Species name & Ascomata & Hamathecium & Asci & Ascospores & Host/Substrates/Location & References \\
\hline L. bruneiense & $\begin{array}{l}1,060 \mu \mathrm{m} \text { diameter } \times \\
340 \mu \mathrm{m} \text { high }\end{array}$ & $2.5 \mu \mathrm{m}$ diameter & $\begin{array}{l}224.4-265.2 \mu \mathrm{m} \times \\
10.2-15.3 \mu \mathrm{m}\end{array}$ & $\begin{array}{l}(117.3-) 126.2-159.4 \\
\times(2.6-) 3.1-3.8(-4.6) \\
\mu \mathrm{m}, \text { a small mucilage } \\
\text { appendage at both } \\
\text { tips, rounded end, a } \\
\text { crescent-shape pad } \\
\text { while the narrower } \\
\text { end has a flame- } \\
\text { shaped appendage }\end{array}$ & $\begin{array}{l}\text { On dead petiole of } \\
\text { Calamus pogonacanthus } \\
\text { (Arecaceae) } \\
\text { Brunei }\end{array}$ & $\begin{array}{l}\text { Fröhlich \& Hyde } \\
2000\end{array}$ \\
\hline L. cajani & $\begin{array}{l}325-390 \mu \mathrm{m} \text { diameter } \\
\times 130-260 \mu \mathrm{m} \text { high }\end{array}$ & $\begin{array}{l}5 \mu \mathrm{m} \text { at the base, } 2 \\
\mu \mathrm{m} \text { at the apex }\end{array}$ & $82-100 \times 7-10 \mu \mathrm{m}$ & $\begin{array}{l}50-80 \times 1.5-2.5 \mu \mathrm{m} \\
\text { diameter, both ends } \\
\text { rounded with a small } \\
\text { mucilaginous pad at } \\
\text { each end }\end{array}$ & $\begin{array}{l}\text { On dry stalks of Cajanus } \\
\text { cajan (Fabaceae), Elaeis } \\
\text { guineensis (Arecaceae) } \\
\text { Papua New Guinea, } \\
\text { Tanzania }\end{array}$ & $\begin{array}{l}\text { Petrak \& Deighton } \\
\text { 1952, Pirozynski } \\
\text { 1972, Hyde 1992a }\end{array}$ \\
\hline L. calamicola & $\begin{array}{l}542-587 \mu \mathrm{m} \text { diameter } \\
\times 310-368 \mu \mathrm{m} \text { high }\end{array}$ & $\begin{array}{l}3.8-4.4 \mu \mathrm{m} \text { diameter } \\
\text { at the base }\end{array}$ & $\begin{array}{l}178-240 \times 8-11.2(- \\
14.35) \mu \mathrm{m}\end{array}$ & $\begin{array}{l}97.9-117.45 \times 2-2.6 \\
\mu \mathrm{m}, \text { a mucilaginous } \\
\text { pad at the base, with } \\
\text { bipolar pads at } \\
\text { maturity }\end{array}$ & $\begin{array}{l}\text { On dead rattan of Calamus } \\
\text { australis, C.conirostris, } \\
\text { Archontophoenix } \\
\text { alexandrae (Arecaceae) } \\
\text { Australia, Queensland }\end{array}$ & $\begin{array}{l}\text { Fröhlich \& Hyde } \\
\text { 2000, Taylor \& } \\
\text { Hyde } 2003\end{array}$ \\
\hline${ }^{*, \$}$ L. carinisporum & $\begin{array}{l}560 \mu \mathrm{m} \text { diameter } \times \\
160 \mu \mathrm{m} \text { high }\end{array}$ & up to $6 \mu \mathrm{m}$ at the base & $110-160 \times 8-11 \mu \mathrm{m}$ & $\begin{array}{l}84-98 \times 2.4-3.2 \mu \mathrm{m}, \\
\text { with or without } \\
\text { refringent septum- } \\
\text { like bands, rounded } \\
\text { and swollen at the } \\
\text { apex, basally narrow } \\
\text { (cone-shaped) with a } \\
\text { keel-like } \\
\text { mucilaginous } \\
\text { appendage }\end{array}$ & $\begin{array}{l}\text { On dead rachis of Licuala } \\
\text { ramsayi, Cocos nucifera, } \\
\text { Calamus conirostris, } \\
\text { Calamus pogonacanthus } \\
\text { (Arecaceae) } \\
\text { Peninsular Malaysia, } \\
\text { Australia, Brunei } \\
\text { Darussalam }\end{array}$ & $\begin{array}{l}\text { Hyde } 1997, \\
\text { Froehlich \& Hyde } \\
\text { 2000, Taylor \& } \\
\text { Hyde 2003, Bahl } \\
2006\end{array}$ \\
\hline${ }^{*}, \$$ L. clavatum & $\begin{array}{l}360 \mu \mathrm{m} \text { diameter } \times \\
160 \mu \mathrm{m} \text { high }\end{array}$ & up to $4 \mu \mathrm{m}$ at the base & $\begin{array}{l}74-92 \times 12-17 \mu \mathrm{m}, \\
\text { clavate }\end{array}$ & $\begin{array}{l}41-51 \times 4-5.5 \mu \mathrm{m}, \\
\text { clavate, widest at the } \\
\text { center, lack } \\
\text { appendage, basal } \\
\text { truncate and narrow, } \\
\text { with a mucilaginous } \\
\text { appendage }\end{array}$ & $\begin{array}{l}\text { On rachis of Pinanga } \\
\text { (Arecaceae) } \\
\text { Peninsular Malaysia }\end{array}$ & $\begin{array}{l}\text { Hyde 1997, Bahl } \\
2006\end{array}$ \\
\hline
\end{tabular}


Table 1 Continued.

\begin{tabular}{|c|c|c|c|c|c|c|}
\hline Species name & Ascomata & Hamathecium & Asci & Ascospores & Host/Substrates/Location & References \\
\hline $\begin{array}{l}\text { "L. cocois } \\
\text { MFLU 15-2345 }\end{array}$ & $\begin{array}{l}400-980 \mu \mathrm{m} \text { diameter } \\
\times 73-184 \mu \mathrm{m} \text { high }\end{array}$ & $0.5-1 \mu \mathrm{m}$ diameter & $100-153 \times 8-15 \mu \mathrm{m}$ & $\begin{array}{l}69-90 \times 3-5 \mu \mathrm{m}, \\
\text { without refringent } \\
\text { septum-like bands, } \\
\text { ends rounded, the } \\
\text { base wider than apex }\end{array}$ & $\begin{array}{l}\text { On dead rachis of Cocos } \\
\text { nucifera (Arecaceae) } \\
\text { Thailand }\end{array}$ & In this study \\
\hline${ }^{*}, \$$ L. copelandi & - & - & - & - & $\begin{array}{l}\text { Daemonorops sp. } \\
\text { (Arecaceae) } \\
\text { Brunei }\end{array}$ & Bahl 2006 \\
\hline${ }^{*}, \$$ L. eccentricollum & $\begin{array}{l}233-360 \mu \mathrm{m} \text { diameter } \\
\times 86-160 \mu \mathrm{m} \text { high }\end{array}$ & $\begin{array}{l}2.75-5 \mu \mathrm{m} \text { diameter } \\
\text { at the base }\end{array}$ & $\begin{array}{l}103.75-137.5 \times \\
8.75-11(-13.5) \mu \mathrm{m}\end{array}$ & $\begin{array}{l}68.75-100 \times 2.5-3.25 \\
\mu \mathrm{m}, \text { obvious } \\
\text { mucilage appendage } \\
\text { at the base of the } \\
\text { ascospore only }\end{array}$ & $\begin{array}{l}\text { On dead petiole of } \\
\text { Mauritia flexuosa } \\
\text { (Arecaceae) } \\
\text { Ecuador }\end{array}$ & $\begin{array}{l}\text { Fröhlich \& Hyde } \\
2000, \text { Bahl } 2006\end{array}$ \\
\hline${ }^{*, \$}$ L. elaeidis & $\begin{array}{l}(350-) 450-(480-) 520 \\
\mu \mathrm{m} \text { diameter } \times(150- \\
) 195(-220) \mu \mathrm{m} \text { high }\end{array}$ & $3-3.5 \mu \mathrm{m}$ wide & $\begin{array}{l}(94-) 116-(134-) 148 \\
\times(8-) 9-(10-) 13 \mu \mathrm{m}, \\
\text { clavate-cylindric, } \\
\text { cylindrical }\end{array}$ & $\begin{array}{l}72-(90-) 97 \times(2-) 3- \\
4 \mu \mathrm{m}, \\
\text { mucilage at the base }\end{array}$ & $\begin{array}{l}\text { Dead rachis of Elaeis } \\
\text { guineensis, Calamus } \\
\text { conirostris, C.radicalis, } \\
\text { Calamus sp., Licuala } \\
\text { longicalycata, Mauritia } \\
\text { sp., Phoenix hanceana, } \\
\text { Phoenix sp., Raphia } \\
\text { vinifera, Trachycarpus } \\
\text { fortunei, Trachycarpus sp. } \\
\text { (Arecaceae) } \\
\text { Brazil, Brunei Darussalam, } \\
\text { Australia, Malaysia, Sierra } \\
\text { Leone, Tanzania, Thailand, } \\
\text { Hong Kong }\end{array}$ & $\begin{array}{l}\text { Petrak \& Deighton } \\
\text { 1952, Pirozynski } \\
\text { 1972, Turner } \\
\text { 1971, Liu 1977, } \\
\text { Hyde 1992, } \\
\text { Fröhlich \& Hyde } \\
\text { 2000, Lu et al. } \\
\text { 2000, Zhuang } \\
\text { 2001, Taylor \& } \\
\text { Hyde 2003, Bahl } \\
\text { 2006, Pinruan et } \\
\text { al. } 2007\end{array}$ \\
\hline L. falciformisporum & $\begin{array}{l}500 \mu \mathrm{m} \text { diameter } \times \\
120 \mu \mathrm{m} \text { high }\end{array}$ & $\begin{array}{l}\text { up to } 5 \mu \mathrm{m} \text { wide at the } \\
\text { base }\end{array}$ & $112-140 \times 8-10 \mu \mathrm{m}$ & $\begin{array}{l}33-42 \times 2.5-4.5 \mu \mathrm{m}, \\
2-3-\text { seriate, } \\
\text { appendage } \\
\text { mucilaginous } \\
\text { becoming sickle- } \\
\text { shaped or veil-like in } \\
\text { water }\end{array}$ & $\begin{array}{l}\text { On decaying leaves of } \\
\text { Pandanus in freshwater } \\
\text { swamp (Pandanaceae) } \\
\text { Papua New Guinea, Irian } \\
\text { Jaya }\end{array}$ & Hyde 1997 \\
\hline
\end{tabular}


Table 1 Continued.

\begin{tabular}{|c|c|c|c|c|c|c|}
\hline Species name & Ascomata & Hamathecium & Asci & Ascospores & Host/Substrates/Location & References \\
\hline L. fasciatum & $\begin{array}{l}550-650 \mu \mathrm{m} \text { diameter } \\
\times 140-170 \mu \mathrm{m} \text { high }\end{array}$ & $2-6 \mu \mathrm{m}$ diameter & $110-178 \times 8-14 \mu \mathrm{m}$ & $\begin{array}{l}84-110 \times 2.5-3.5 \mu \mathrm{m}, \\
\text { appendage absent }\end{array}$ & $\begin{array}{l}\text { On fallen leaves of } \\
\text { Pandanus eydouxia } \\
\text { (Pandanaceae) } \\
\text { Mauritius }\end{array}$ & $\begin{array}{l}\text { Dulymamode et } \\
\text { al. } 1998\end{array}$ \\
\hline L. freycinetiae & $\begin{array}{l}280-420 \mu \mathrm{m} \text { diameter } \\
\times 100 \mu \mathrm{m} \text { high }\end{array}$ & poorly preserved & $\begin{array}{l}54-82 \times 7-10 \mu \mathrm{m}, \\
\text { cylindric-clavate }\end{array}$ & $\begin{array}{l}28-32 \times 2.5-3 \mu \mathrm{m}, \\
\text { no appendages } \\
\text { observed }\end{array}$ & $\begin{array}{l}\text { In freshwater swamp on } \\
\text { decaying Pandanus leaves } \\
\text { (Pandanaceae) } \\
\text { Indonesia }\end{array}$ & Hyde 1997 \\
\hline L. hamaspora & $\begin{array}{l}170-220 \mu \mathrm{m} \text { diameter } \\
\times 120-150 \mu \mathrm{m} \text { high }\end{array}$ & deliquescent & $44-66 \times 8-11 \mu \mathrm{m}$ & $\begin{array}{l}38.5-50 \times 1-2 \mu \mathrm{m} \text {, } \\
\text { with an obtuse apex } \\
\text { and tapering to the } \\
\text { base }\end{array}$ & $\begin{array}{l}\text { On leaves of Quercus } \\
\text { tinctoria (Fagaceae) } \\
\text { Great Smoky Mountains } \\
\text { National Park (U.S. } \\
\text { National Park Service) }\end{array}$ & $\begin{array}{l}\text { Barr 1993, Hyde } \\
1997\end{array}$ \\
\hline L. lammiae & $\begin{array}{l}420-485 \mu \mathrm{m} \text { diameter } \\
\times 190-202 \mu \mathrm{m} \text { high }\end{array}$ & 3-7 $\mu \mathrm{m}$ diameter & $97-133 \times 13.5-26 \mu \mathrm{m}$ & $\begin{array}{l}53-76 \times 4.5-7 \mu \mathrm{m}, \\
\text { without visible } \\
\text { gelatinous appendages }\end{array}$ & $\begin{array}{l}\text { On decaying leaves of } \\
\text { Pandanus tectorius } \\
\text { (Pandanaceae) } \\
\text { Queensland, Australia }\end{array}$ & $\begin{array}{l}\text { Thongkantha et } \\
\text { al. } 2003\end{array}$ \\
\hline${ }^{*, \$}$ L. livistonae & $\begin{array}{l}\text { up to } 700 \mu \mathrm{m} \\
\text { diameter } \times 195 \mu \mathrm{m} \\
\text { high }\end{array}$ & $\begin{array}{l}\text { embedded in a gel, } \\
\text { wide }\end{array}$ & $\begin{array}{l}100-140 \times 6-12 \mu \mathrm{m}, \\
\text { whitish in mass, } \\
\text { short-pediculate }\end{array}$ & $\begin{array}{l}70-104 \times 1.6-2.3 \mu \mathrm{m}, \\
\text { apex rounded, the } \\
\text { base narrow with } \\
\text { mucilage }\end{array}$ & $\begin{array}{l}\text { Pandanus (Pandanaceae), } \\
\text { Livistona chinensis, } \\
\text { Livistona sp., Arenga } \\
\text { engleri, Archontophoenix } \\
\text { alexandrae, Licuala } \\
\text { longicalycata, } \\
\text { Ptychosperma sp., } \\
\text { (Arecaceae) } \\
\text { Philippines, Mindanao } \\
\text { Island, Taiwan, Australia, } \\
\text { Thailand, Indonesia }\end{array}$ & $\begin{array}{l}\text { Hyde 1989, } \\
\text { 1992a, Bahl } \\
\text { 2006, Taylor \& } \\
\text { Hyde 2003, } \\
\text { Pinruan et al. } \\
2007\end{array}$ \\
\hline L. longisporum & $\begin{array}{l}585-780 \mu \mathrm{m} \text { diameter } \\
\times 130-210 \mu \mathrm{m} \text { high }\end{array}$ & $\begin{array}{l}6 \mu \mathrm{m} \text { at the base, } 2 \\
\mu \mathrm{m} \text { at the apex }\end{array}$ & $\begin{array}{l}170-216 \times 8-12 \mu \mathrm{m}, \\
\text { long-pediculate }\end{array}$ & $\begin{array}{l}124-140 \times 2.5-3.0 \\
\mu \mathrm{m}, \text { one end rounded, } \\
\text { one end tapering with } \\
\text { mucilage, curved, C- } \\
\text { shaped or sigmoid, } \\
\text { very rarely } 1 \text {-septate } \\
\text { in the center }\end{array}$ & $\begin{array}{l}\text { On intertidal fronds of } \\
\text { Nypa fruticans (Arecaceae) } \\
\text { Brunei }\end{array}$ & Hyde $1992 \mathrm{a}$ \\
\hline
\end{tabular}


Table 1 Continued.

\begin{tabular}{|c|c|c|c|c|c|c|}
\hline Species name & Ascomata & Hamathecium & Asci & Ascospores & Host/Substrates/Location & References \\
\hline L. luteocollum & $\begin{array}{l}260-425 \mu \mathrm{m} \text { diameter } \\
\times 70-130 \mu \mathrm{m} \text { high }\end{array}$ & $2-5 \mu \mathrm{m}$ & $156-186 \times 7.6-10 \mu \mathrm{m}$ & $\begin{array}{l}88-107 \times 2-2.8 \mu \mathrm{m}, \\
\text { parallel in asci, } \\
\text { rounded apex, } \\
\text { attenuated base with } \\
\text { small mucilaginous } \\
\text { pad, lacking or } \\
\text { present refringent } \\
\text { septum-like bands }\end{array}$ & $\begin{array}{l}\text { On dead rachis of } \\
\text { Archontophoenix } \\
\text { alexandrae (Arecaceae) } \\
\text { Australia, Queensland }\end{array}$ & $\begin{array}{l}\text { Taylor \& Hyde } \\
2003\end{array}$ \\
\hline L. manihotis & 150-300 $\mu \mathrm{m}$ diameter & - & $50-90 \mu \mathrm{m} \times 5-10 \mu \mathrm{m}$ & $45-70 \times 1-1.5 \mu \mathrm{m}$ & $\begin{array}{l}\text { Manihot utilissima } \\
\text { (Manihotis utilissimae) } \\
\text { (Euphorbiaceae) } \\
\text { India, Travancore, } \\
\text { Pulliyanur }\end{array}$ & Petrak 1956 \\
\hline L. mauritiae & $\begin{array}{l}360-472 \mu \mathrm{m} \text { diameter } \\
\times 152-232 \mu \mathrm{m} \text { high }\end{array}$ & $\begin{array}{l}1.5-2.5 \mu \mathrm{m} \text { diameter } \\
\text { at the base }\end{array}$ & $125-170 \times 10-12 \mu \mathrm{m}$ & $\begin{array}{l}82.5-107.5 \times 2-2.8 \\
\mu \mathrm{m}, \text { neither ascospore } \\
\text { end has a } \\
\text { mucilaginous } \\
\text { appendage }\end{array}$ & $\begin{array}{l}\text { On dead petiole of } \\
\text { Mauritia flexuosa } \\
\text { (Arecaceae) } \\
\text { Ecuador }\end{array}$ & $\begin{array}{l}\text { Fröhlich \& Hyde } \\
2000\end{array}$ \\
\hline L. nipae & $\begin{array}{l}465-620 \mu \mathrm{m} \text { diameter } \\
\times 150-290 \mu \mathrm{m} \text { high }\end{array}$ & wide at the base & $\begin{array}{l}147-221 \times 11.7-18.2 \\
\mu \mathrm{m}, \text { long-cylindrical, } \\
\text { strongly curved, long- } \\
\text { pediculate }\end{array}$ & $\begin{array}{l}91-123.5 \times 2.6-4.3 \\
\mu \mathrm{m}, \text { yellowish in } \\
\text { mass, mucilage at } \\
\text { basal }\end{array}$ & $\begin{array}{l}\text { Nypa fruticans } \\
\text { (Arecaceae) } \\
\text { Philippines, Luzon, } \\
\text { Pampanga, Brunei } \\
\text { Darussalam }\end{array}$ & $\begin{array}{l}\text { Hyde 1989, } \\
1992 \mathrm{a}\end{array}$ \\
\hline L. palmetto & $325-429 \mu \mathrm{m}$ diameter & wide at the base & $70-100 \times 8-10 \mu \mathrm{m}$ & $\begin{array}{l}50-56 \times 2.5-3.5 \mu \mathrm{m}, \\
\text { hyaline in mass, one } \\
\text { end wider with } \\
\text { mucilage at the base }\end{array}$ & $\begin{array}{l}\text { On dead places in living } \\
\text { leaves of Sabal palmetto } \\
\text { (Arecaceae) } \\
\text { United States, Langlois, } \\
\text { Oregon, Louisiana }\end{array}$ & $\begin{array}{l}\text { Barr 1978, Hyde } \\
1992\end{array}$ \\
\hline $\begin{array}{l}\#,{ }^{*}, \text { L. pandani } \\
\text { (type species) }\end{array}$ & $\begin{array}{l}\text { up to } 600-650 \mu \mathrm{m} \\
\text { diameter } \times 200-300 \\
\mu \mathrm{m} \text { high }\end{array}$ & $3-4 \mu \mathrm{m}$ wide at base & $\begin{array}{l}100-140 \times 8-10 \mu \mathrm{m}, \\
\text { long cylindrical }\end{array}$ & $\begin{array}{l}62-80 \times 2-4 \mu \mathrm{m}, \\
\text { centrally wide, ends } \\
\text { rounded, parallel or } \\
\text { spiral, without } \\
\text { gelatinous appendages } \\
\text { or mucilage }\end{array}$ & $\begin{array}{l}\text { Pandanus leaves } \\
\text { (Pandanaceae), Arenga } \\
\text { engleri, Licuala } \\
\text { longicalycata, } \\
\text { Ptychosperma sp. } \\
\text { (Arecaceae) } \\
\text { Hong Kong, Thailand, } \\
\text { Taiwan }\end{array}$ & $\begin{array}{l}\text { Sydow \& Sydow } \\
\text { 1917, Sivanesan } \\
\text { \& Hsieh 1989, } \\
\text { Hyde 1992a, } \\
\text { Bahl 2006, } \\
\text { Pinruan et al. } \\
2007\end{array}$ \\
\hline
\end{tabular}


Table 1 Continued.

\begin{tabular}{|c|c|c|c|c|c|c|}
\hline Species name & Ascomata & Hamathecium & Asci & Ascospores & Host/Substrates/Location & References \\
\hline "L. pandanicola & $\begin{array}{l}700-800 \mu \mathrm{m} \text { diameter } \\
\times 185-260 \mu \mathrm{m} \text { high }\end{array}$ & $\begin{array}{l}\text { up to } 6 \mu \mathrm{m} \text { wide at the } \\
\text { base }\end{array}$ & $160-190 \times 8-10 \mu \mathrm{m}$ & $\begin{array}{l}72-100 \times 2.6-3.2 \mu \mathrm{m}, \\
\text { with a small } \\
\text { mucilaginous pad }\end{array}$ & $\begin{array}{l}\text { Pandanus decaying leaves, } \\
\text { in freshwater swamp } \\
\text { (Pandanaceae), } \\
\text { Archontophoenix } \\
\text { alexandrae, Mauritia } \\
\text { flexuosa, Phoenix } \\
\text { hanceana, Phoenix sp. } \\
\text { (Arecaceae) } \\
\text { Papua New Guinea (Iryan } \\
\text { Jaya), Australia, Ecuador }\end{array}$ & $\begin{array}{l}\text { Hyde } 1997, \\
\text { Froehlich \& } \\
\text { Hyde } 2000, \text { Lu et } \\
\text { al. 2000, Zhuang } \\
\text { 2001, Taylor \& } \\
\text { Hyde } 2003\end{array}$ \\
\hline L. siamense & $\begin{array}{l}575-825 \mu \mathrm{m} \text { diameter } \\
\times 650-875 \mu \mathrm{m} \text { high }\end{array}$ & $3.1-12.3 \mu \mathrm{m}$ & $\begin{array}{l}100-156 \times 7.7-9.3 \\
\mu \mathrm{m},\end{array}$ & $\begin{array}{l}59-71 \times 3.1-3.3 \mu \mathrm{m}, \\
\text { with appendage }\end{array}$ & $\begin{array}{l}\text { On decaying leaves of } \\
\text { Pandanus penetrans } \\
\text { (Pandanaceae) } \\
\text { Thailand }\end{array}$ & $\begin{array}{l}\text { Thongkantha et } \\
\text { al. } 2003\end{array}$ \\
\hline L. smilacis & $\begin{array}{l}300-350 \mu \mathrm{m} \text { diameter } \\
\times 300-400 \mu \mathrm{m} \text { high }\end{array}$ & $2-5 \mu \mathrm{m}$ wide & $150-160 \times 7-10 \mu \mathrm{m}$ & $\begin{array}{l}120-130 \times 2-2.5 \mu \mathrm{m} \text {, } \\
\text { ends rounded }\end{array}$ & $\begin{array}{l}\text { On dead stems of Smilax } \\
\text { (Smilacaceae) } \\
\text { Taiwan }\end{array}$ & Hsieh et al. 1998 \\
\hline L. spathulatum & $\begin{array}{l}240-320 \mu \mathrm{m} \text { diameter } \\
\times 70-100 \mu \mathrm{m} \text { high }\end{array}$ & $3.5-4.5 \mu \mathrm{m}$ wide & $\begin{array}{l}110-170 \times 12-16 \\
\mu \mathrm{m}\end{array}$ & $\begin{array}{l}66-89 \times 4-5.5(-6) \mu \mathrm{m}, \\
\text { the appendage tip } \\
\text { rounded }\end{array}$ & $\begin{array}{l}\text { On dead leaf of Pandanus } \\
\text { palustris (Pandanaceae) } \\
\text { Mauritius }\end{array}$ & $\begin{array}{l}\text { Dulymamode et } \\
\text { al. } 1998\end{array}$ \\
\hline L. stipae & - & - & - & - & $\begin{array}{l}\text { On dead culms of Stipa sp. } \\
\text { (Poaceae) } \\
\text { South Australia }\end{array}$ & Hansford 1954 \\
\hline L. sulcatum & $\begin{array}{l}260-340 \mu \mathrm{m} \text { diameter } \\
\times 70-130 \mu \mathrm{m} \text { high }\end{array}$ & $\begin{array}{l}2-4 \mu \mathrm{m} \text { wide, rarely } \\
\text { branched }\end{array}$ & $92-170 \times 12-20 \mu \mathrm{m}$ & $\begin{array}{l}76-107 \times 3-4 \mu \mathrm{m}, \\
\text { with a basal appendage }\end{array}$ & $\begin{array}{l}\text { On dead leaves of } \\
\text { Pandanus barklyi } \\
\text { (Pandanaceae) } \\
\text { Mauritius }\end{array}$ & $\begin{array}{l}\text { Dulymamode et } \\
\text { al. } 1998\end{array}$ \\
\hline L. suthepense & $300-485 \mu \mathrm{m}$ diameter & $4.6-7.7 \mu \mathrm{m}$ & $\begin{array}{l}77-92.5 \times 61-7.7 \\
\mu \mathrm{m}\end{array}$ & $\begin{array}{l}18.5-30.8 \times 2.3-3.1 \\
\mu \mathrm{m}, \text { with appendage }\end{array}$ & $\begin{array}{l}\text { On dead leaves of } \\
\text { Pandanus penetrans } \\
\text { (Pandanaceae) } \\
\text { Thailand }\end{array}$ & $\begin{array}{l}\text { Thongkantha et } \\
\text { al. } 2003\end{array}$ \\
\hline L. verminosum & $\begin{array}{l}\text { Up to } 600 \mu \mathrm{m} \\
\text { diameter }\end{array}$ & - & $70-102 \times 9-12 \mu \mathrm{m}$ & $\begin{array}{l}60-88 \times 1.9-3.2 \mu \mathrm{m}, \\
\text { spiral in asci, hyaline in } \\
\text { mass, lacking mucilage }\end{array}$ & $\begin{array}{l}\text { In petioles of palms and } \\
\text { Sabal palmetto, } \\
\text { Guiana, Cayenne, Florida }\end{array}$ & $\begin{array}{l}\text { Schrantz 1960, } \\
\text { Hyde 1989, } \\
1992 \text { a }\end{array}$ \\
\hline
\end{tabular}


Table 1 Continued.

\begin{tabular}{|c|c|c|c|c|c|c|}
\hline Species name & Ascomata & Hamathecium & Asci & Ascospores & Host/Substrates/Location & References \\
\hline L. versisporum & $250-333 \mu \mathrm{m}$ diameter & $\begin{array}{l}\text { embedded in a gel, } \\
\text { wide }\end{array}$ & $70-80 \times 8-9 \mu \mathrm{m}$ & $\begin{array}{l}60-70 \times 2-2.5 \mu \mathrm{m}, \\
\text { pale yellow, without } \\
\text { septate }\end{array}$ & $\begin{array}{l}\text { On dead petioles of Sabal } \\
\text { serrulata (Arecaceae) } \\
\text { Florida }\end{array}$ & Petrak 1952 \\
\hline L. williamsii & - & - & - & - & $\begin{array}{l}\text { On dead culms of Gramineae } \\
\text { (Poaceae) } \\
\text { South Australia }\end{array}$ & Hansford 1954 \\
\hline L. zingiberacicola & $\begin{array}{l}600 \mu \mathrm{m} \text { diameter } \times \\
320 \mu \mathrm{m} \text { high }\end{array}$ & $\begin{array}{l}\text { up to } 4 \mu \mathrm{m} \text { at the } \\
\text { base }\end{array}$ & $\begin{array}{l}140-180 \times 9-12 \\
\mu \mathrm{m}\end{array}$ & $\begin{array}{l}102-120 \times 2.4-3 \mu \mathrm{m}, \\
\text { mostly curved, the ends } \\
\text { rounded with mucilage }\end{array}$ & $\begin{array}{l}\text { On basal stem of Zingiberaceae } \\
\text { Malaysia, Peninsular }\end{array}$ & Hyde 1997 \\
\hline $\begin{array}{l}\text { "Neolinocarpon } \\
\text { arengae } \\
\text { MFLU 15-0298 }\end{array}$ & $\begin{array}{l}230-490 \mu \mathrm{m} \text { diameter } \\
\times 336-566 \mu \mathrm{m} \text { high }\end{array}$ & $2-4 \mu \mathrm{m}$ diameter & $\begin{array}{l}168-214 \times 15-21 \\
\mu \mathrm{m}\end{array}$ & $\begin{array}{l}114-134 \times 3-4 \mu \mathrm{m} \text {, } \\
\text { ends rounded, with polar } \\
\text { mucilaginous appendage } \\
\text { at apex }\end{array}$ & $\begin{array}{l}\text { On dead leaflet of Arenga } \\
\text { pinnata (Arecaceae) } \\
\text { Thailand }\end{array}$ & In this study \\
\hline N. attaleae & $\begin{array}{l}350-880 \times 220-650 \\
\mu \mathrm{m}\end{array}$ & up to $5 \mu \mathrm{m}$ & $\begin{array}{l}137.5-227.5 \times \\
7.5-14(-15) \mu \mathrm{m}\end{array}$ & $\begin{array}{l}(52.5-) 57.5-93(-105) \times \\
3-4(-5) \mu \mathrm{m}, \\
\text { filiform-fusoid to } \\
\text { clavate, lack appendages }\end{array}$ & $\begin{array}{l}\text { On dead rachis of Attalea } \\
\text { funifera (Arecaceae) } \\
\text { Brazil, Bahia }\end{array}$ & $\begin{array}{l}\text { Vitoria et al. } \\
2013\end{array}$ \\
\hline N. australiense & $\begin{array}{l}560-616(-760) \mu \mathrm{m} \\
\text { diameter } \times(204- \\
) 296-380 \mu \mathrm{m} \text { high }\end{array}$ & $\begin{array}{l}\text { deliquescing during } \\
\text { maturation }\end{array}$ & $\begin{array}{l}125-164 \times 11-15 \\
\mu \mathrm{m}\end{array}$ & $\begin{array}{l}81-107(-126) \times 2.5-3.5 \\
\mu \mathrm{m}, \text { base narrower than } \\
\text { apex with an } \\
\text { inconspicuous, keel-like } \\
\text { mucilaginous appendage, } \\
\text { lacking appendage }\end{array}$ & $\begin{array}{l}\text { On dead rattan of Calamus } \\
\text { moti, Calamus australis, } \\
\text { Arenga engleri, Arenga sp., } \\
\text { Livistona chinensis (Arecaceae) } \\
\text { Australia, North Queensland, } \\
\text { Hong Kong }\end{array}$ & $\begin{array}{l}\text { Hyde et al. } \\
1998, \text { Lu et al. } \\
2000, \text { Zhuang } \\
2001\end{array}$ \\
\hline${ }^{* \$} N$. calami & $\begin{array}{l}448-500 \mu \mathrm{m} \text { diameter } \\
\times 292-336 \mu \mathrm{m} \text { high }\end{array}$ & - & $\begin{array}{l}115-138 \times 10.5- \\
13 \mu \mathrm{m}\end{array}$ & $\begin{array}{l}68-85 \times 2.5-3.5 \mu \mathrm{m}, \\
\text { swollen blunt base, } \\
\text { rounded apex, crescent- } \\
\text { shaped mucilage pad at } \\
\text { end, lacking at the } \\
\text { rounded end }\end{array}$ & $\begin{array}{l}\text { On dead petiole of Calamus } \\
\text { conirostris (Arecaceae) } \\
\text { Brunei }\end{array}$ & $\begin{array}{l}\text { Hyde et al. } \\
\text { 1998, Bahl } 2006\end{array}$ \\
\hline${ }^{*, \$} N$. enshiense & $\begin{array}{l}225-335 \mu \mathrm{m} \text { diameter } \\
\times 200-260 \mu \mathrm{m} \text { high }\end{array}$ & $\begin{array}{l}2-3.6 \mu \mathrm{m} \text { at the } \\
\text { base }\end{array}$ & $\begin{array}{l}74-108 \times 8-13 \\
\mu \mathrm{m}\end{array}$ & $\begin{array}{l}42-64 \times 2-3.5 \mu \mathrm{m}, \text { apex } \\
\text { rounded, truncate with a } \\
\text { small mucilaginous pad }\end{array}$ & $\begin{array}{l}\text { On dead petiole of } \\
\text { Trachycarpus fortunei } \\
\text { (Arecaceae) } \\
\text { China, south west Hubei, Enshi }\end{array}$ & $\begin{array}{l}\text { Hyde et al. } \\
\text { 1998, Bahl } 2006\end{array}$ \\
\hline
\end{tabular}


Table 1 Continued.

\begin{tabular}{|c|c|c|c|c|c|c|}
\hline Species name & Ascomata & Hamathecium & Asci & Ascospores & Host/Substrates/Location & References \\
\hline N. eutypoides & $\begin{array}{l}204-312 \mu \mathrm{m} \text { diameter } \\
\times 544-576 \mu \mathrm{m} \text { high }\end{array}$ & $\begin{array}{l}\text { up to } 5.2 \mu \mathrm{m} \text { wide at } \\
\text { the base, tapering to } \\
1-2.9 \mu \mathrm{m} \text { at the tip }\end{array}$ & $108-138 \times 6-8.5 \mu \mathrm{m}$ & $\begin{array}{l}73-95(-106) \times 1.5- \\
2.2(-2.5) \mu \mathrm{m}, \\
\text { rounded apex towards } \\
\text { the flexuose or } \\
\text { pointed base, } \\
\text { mucilaginous } \\
\text { appendage }\end{array}$ & $\begin{array}{l}\text { Acrocomia sclerocarpa, } \\
\text { Archontophoenix } \\
\text { alexandrae, Calamus } \\
\text { conirostris, Cocos nucifera, } \\
\text { Daemonorops margaritae, } \\
\text { Licuala spp., Livistona } \\
\text { chinensis, Plectocomia } \\
\text { elongata (Arecaceae) } \\
\text { Australia, Brunei } \\
\text { Darussalam, Hong Kong, } \\
\text { Indonesia, Malaysia }\end{array}$ & $\begin{array}{l}\text { Hyde et al. } 1998, \\
\text { Lu et al. } 2000\end{array}$ \\
\hline $\begin{array}{l}\#, *, \$ N . \text { globosicarpum } \\
\text { (type species) }\end{array}$ & $\begin{array}{l}155-400 \mu \mathrm{m} \text { diameter } \\
\times 310-520 \mu \mathrm{m} \text { high }\end{array}$ & $\begin{array}{l}5.6 \mu \mathrm{m} \text { diameter at the } \\
\text { base }\end{array}$ & $136-170 \times 11-12 \mu \mathrm{m}$ & $\begin{array}{l}70-119.3 \times 2.0-2.8 \\
\mu \mathrm{m}, \text { one end rounded, } \\
\text { the other end irregular } \\
\text { with a mucilaginous } \\
\text { appendage }\end{array}$ & $\begin{array}{l}\text { On decaying intertidal } \\
\text { fronds of Nypa fruticans } \\
\text { (Arecaceae) } \\
\text { Brunei, South China Sea }\end{array}$ & $\begin{array}{l}\text { Hyde } 1992 b, \\
\text { Bahl 2006, } \\
\text { Jasrotia et al. } \\
2014\end{array}$ \\
\hline N. inconspicuum & $\begin{array}{l}200-255 \mu \mathrm{m} \text { diameter } \\
\times 365-410 \mu \mathrm{m} \text { high }\end{array}$ & $\begin{array}{l}2.6-6 \mu \mathrm{m} \text { diameter at } \\
\text { the base }\end{array}$ & $106-156 \times 7.5-12 \mu \mathrm{m}$ & $76-98 \times 2-3 \mu \mathrm{m}$ & $\begin{array}{l}\text { On dead rachis of } \\
\text { Archontophoenix } \\
\text { alexandrae (Arecaceae) } \\
\text { Australia, Queensland }\end{array}$ & Hyde et al. 1998 \\
\hline $\begin{array}{l}{ }^{*} \$ \\
\text { nonappendiculatum }\end{array}$ & $\begin{array}{l}635-710 \mu \mathrm{m} \text { diameter } \\
\times 375-520 \mu \mathrm{m} \text { high }\end{array}$ & $\begin{array}{l}2.8-4 \mu \mathrm{m} \text { diameter at } \\
\text { the base }\end{array}$ & $134-190 \times 8.5-12 \mu \mathrm{m}$ & $114-138 \times 2-2.5 \mu \mathrm{m}$ & $\begin{array}{l}\text { On dead petiole of } \\
\text { Archontophoenix } \\
\text { alexandrae (Arecaceae) } \\
\text { Australia, Queensland, } \\
\text { Singapore }\end{array}$ & $\begin{array}{l}\text { Hyde et al. 1998, } \\
\text { Bahl } 2006\end{array}$ \\
\hline N. nypicola & $\begin{array}{l}600-1,000 \mu \mathrm{m} \\
\text { diameter }\end{array}$ & $\begin{array}{l}5-8.8 \mu \mathrm{m} \text { diameter at } \\
\text { the base }\end{array}$ & $100-164 \times 8-10 \mu \mathrm{m}$, & $\begin{array}{l}92-117 \times 2-3.8 \mu \mathrm{m}, \\
\text { cream color in mass }\end{array}$ & $\begin{array}{l}\text { On dead aerial rachids of } \\
\text { Nypa fruticans (Arecaceae) } \\
\text { Malaysia, Kuala Selangor }\end{array}$ & $\begin{array}{l}\text { Hyde \& Alias } \\
1999\end{array}$ \\
\hline N. penniseti & - & - & - & - & $\begin{array}{l}\text { On dead stem of } \\
\text { Pennisetum purpureum } \\
\text { (Poaceae) } \\
\text { Hong Kong }\end{array}$ & $\begin{array}{l}\text { Bhilabutra et al. } \\
2006\end{array}$ \\
\hline $\begin{array}{l}{ }^{*} N . \text { rachidis } \\
\text { MFLU 15-0307 }\end{array}$ & $\begin{array}{l}320-390 \mu \mathrm{m} \text { diameter } \\
\times 508-590 \mu \mathrm{m} \text { high }\end{array}$ & $2.5-4 \mu \mathrm{m}$ diameter & $157-205 \times 9-19 \mu \mathrm{m}$ & $\begin{array}{l}123-140 \times 2-4, \\
\text { apex rounded, pointed } \\
\text { at the base, appendage }\end{array}$ & $\begin{array}{l}\text { On dead rachis of Arenga } \\
\text { pinnata (Arecaceae) } \\
\text { Thailand }\end{array}$ & In this study \\
\hline
\end{tabular}

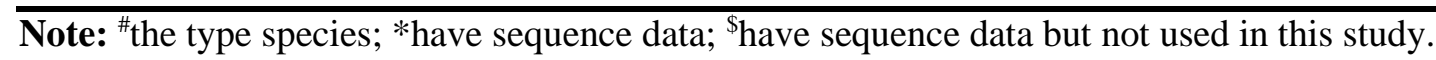


and EF1-983F and EF1-2218R to amplify the fragment of translation elongation factor 1- $\alpha$ (TEF1a) (Rehner \& Buckley 2005).

Polymerase chain reaction (PCR) amplification was carried out as follows: the final volume of the PCR reaction was $25 \mu \mathrm{l}$, which contained $1 \mu \mathrm{l}$ of DNA template, $1 \mu \mathrm{l}$ of each forward and reverse primers, $12.5 \mu \mathrm{l}$ of $2 \times$ Power Taq PCR Master Mix and $9.5 \mu \mathrm{l}$ distilled deionized water. The PCR thermal cycle program of ITS, LSU, and SSU genes amplifications were provided as: initially $94{ }^{\circ} \mathrm{C}$ for $3 \mathrm{~min}$, followed by 35 cycles of denaturation at $94{ }^{\circ} \mathrm{C}$ for $30 \mathrm{~s}$, annealing at 55 ${ }^{\circ} \mathrm{C}$ for $50 \mathrm{~s}$, elongation at $72{ }^{\circ} \mathrm{C}$ for $1 \mathrm{~min}$, and final extension at $72{ }^{\circ} \mathrm{C}$ for $10 \mathrm{~min}$. The PCR thermal cycle program for the RPB2 gene was provided as initially $95^{\circ} \mathrm{C}$ for $5 \mathrm{~min}$, followed by 35 cycles of denaturation at $95{ }^{\circ} \mathrm{C}$ for $1 \mathrm{~min}$, annealing at $52{ }^{\circ} \mathrm{C}$ for $2 \mathrm{~min}$, elongation at $72{ }^{\circ} \mathrm{C}$ for 90 $\mathrm{s}$, and final extension at $72{ }^{\circ} \mathrm{C}$ for $10 \mathrm{~min}$. The PCR thermal cycle program for TEF1- $\alpha$ was set for denaturation at $96^{\circ} \mathrm{C}$ for 2 minutes, followed by 40 cycles of denaturation at $96^{\circ} \mathrm{C}$ for 45 seconds, annealing at $52^{\circ} \mathrm{C}$ for 30 seconds and extension at $72^{\circ} \mathrm{C}$ for 1.30 minutes, with a final extension step at $72^{\circ} \mathrm{C}$ for 5 minutes. Amplified PCR fragments were sequenced at the company. Generated new sequences of ITS, SSU, LSU, RPB2, and TEF1- $\alpha$ regions were deposited in GenBank.

\section{Sequence alignment and phylogenetic analyses}

DNA sequences were aligned in BioEdit (Hall 2004). Based on blast searches in GenBank, using LSU or ITS sequence data, separate phylogenetic analyses were carried out to determine the phylogeny of each fungal group within Sordariomycetes. Supplementary sequences were downloaded from GenBank, based on blast search and recent publications.

Multigene sequence alignments were generated with MAFFT v. 7.215 (Katoh \& Standley 2013, http://mafft.cbrc.jp/alignment/server/index.html) and edited manually when necessary in MEGA7 version 7.0 (Kumar et al. 2016) or BioEdit v. 7.0 (Hall 2004). ITS and LSU sequence datasets were selected to construct the phylogenetic tree, were first analyzed separately and then the individual datasets were concatenated into a combined dataset and prepared in MEGA7 (Kumar et al. 2016). Data were converted from fasta to nexus format with Alignment Transformation Environment online, ALTER (Glez-Peña et al. 2010, https://sing.ei.uvigo.es/ALTER/).

Maximum likelihood analysis was performed by RAxMl GUI v.1.0. (Stamatakis 2006, Silvestro \& Michalak 2011). Alignments in PHYLIP format were exchanged and loaded from the website (http://sing.ei.uvigo.es/ALTER/) (Glez-Peña et al. 2010). The search strategy was set to rapid bootstrapping at 1,000 and the analysis carried out using the GTR-GAMMA model of nucleotide substitution. The model of evolution was determined with MrModeltest 2.2 (Nylander 2004) under the Akaike information criterion (AIC). The model selected was GTR+I+G for each of gene and the combined dataset (Nylander 2004). The number of replicates was inferred using the stopping criterion. Bootstrap values greater than $50 \%$ were accepted. The posterior probabilities (PP) were determined by Markov Chain Monte Carlo sampling (BMCMC) using MrBayes v3.1.2 (Huelsenbeck \& Ronquist 2001). Six simultaneous Markov chains were run for ten million generations and trees sampling frequency of every 1,000 generations. The first 10,000 trees were excluded as burn-in phase based on suggestion from Tracer. Bayesian posterior probabilities (BYPP) were calculated from the remaining 5,000 trees and values greater than 0.95 were accepted. The phylogenetic tree was visualized by FigTree v1.4.0 (Rambaut 2006).

\section{Results}

\section{Phylogenetic analyses}

The combined ITS and LSU sequence dataset alignment including our new taxa comprise taxa from related Sordariomycetes species. Members from Boliniales are a basal clade in this tree. Phylogenetic trees were generated by maximum likelihood (ML) under different optimality criteria, but tree topologies were similar and the best scoring ML with BYPP is shown in Fig. 1. Species of Linocarpon and Neolinocarpon cluster together in a moderately supported clade which we 
established herein as Linocarpaceae fam. nov. Species of Leptosporella form another wellsupported monophyletic clade which we introduce as Leptosporellaceae fam. nov. within Chaetosphaeriales. Our phylogenetic analysis depicts a close relationship of Linocarpon arengae with $L$. cocois with good support (95\% ML, 1.00 BYPP), while related to the sister branches which comprise other species of Linocarpon. Neolinocarpon arengae groups with $N$. rachidis $(96 \% \mathrm{ML}$, 1.00 BYPP). Leptosporella arengae and L. cocois cluster with good bootstrap support (93\% ML). Our six new species show a relationship in Chaetosphaeriales in the phylogenetic tree (Fig. 1).

\section{Taxonomy}

Leptosporellaceae Konta \& K.D. Hyde, fam. nov.

Index Fungorum number: IF553956; Facesoffungi number: FoF03840

Saprobic or endophytic on various plants. Sexual morph: Ascomata solitary, superficial, comprising black, carbonaceous, dome-shaped, raised, blistering areas, within the plant tissues, flattened at the base, ostiole central. Peridium outer cells merging with the host epidermal cells, composed of dark brown to black cells of textura angularis. Hamathecium comprising numerous paraphyses. Asci 8-spored, unitunicate, cylindrical, long-pedicellate, with a $\mathrm{J}^{-}$, wedge-shaped, subapical ring. Ascospores fasciculate, filiform, hyaline or pale-yellowish in mass, aseptate, ends rounded, with or without polar mucilaginous appendages. Asexual morph: Undetermined.

Notes - Species of Leptosporellaceae are mostly saprobic on wood, and have been recorded on stalks of Compositae vivae (Asteraceae), on dead branchlets of a shrub, Rosa, Acacia kempeana (Fabaceae), dead culms of bamboo, dead rachides or petioles of palms, on Clinopodium chinense and Dicksonia squarrosa, and dead leaves of Leucodon sciuroides, an endophytic species have been recovered from eupolypod fern (Polypodiales) (Penzig \& Saccardo 1897, Rehmit 1901, Spegazzini 1912, Chardón \& Toro 1934, Sydow 1938, Chardón 1939, Sousa da Camara \& da Luz 1939, Sawada 1943, Hansford 1957, Racovitza 1959, Edward et al. 1972, Huhndorf et al. 2004, Huhndorf \& Miller 2011, Dai et al. 2016, Del \& Arnold 2017). Our phylogenetic analysis show that Leptosporellaceae species cluster together in a distinct clade, sister to Helminthosphaeriaceae in Chaetosphaeriales (Fig. 1). The new family differs from others families within Chaetosphaeriales as a morphologically and phylogenetically a well-resolved group.

Type genus - Leptosporella Penz. \& Sacc., Malpighia 11(9-10): 406 (1897)

\section{Leptosporella Penz. \& Sacc., 1987}

Saprobic or endophytic on undetermined wood, bamboo (Poaceae), Acacia kempeana (Fabaceae), Clinopodium chinense (Lamiaceae), Dicksonia squarrosa (Dicksoniaceae), Leucodon sciuroides (Leucodontaceae), Rosa (Rosaceae), palms (Arecaceae) and eupolypod ferns (Polypodiales). Sexual morph: Ascomata solitary, superficial, comprising black, carbonaceous, dome-shaped, raised, blistering areas, within the plant tissues, subglobose, flattened at the base, ostiole central. Peridium outer cells merging with the host epidermal cells, composed of dark brown to black cells of textura angularis. Hamathecium comprising numerous, hyaline, hypha-like, septate, paraphyses, longer than asci. Asci 8-spored, unitunicate, cylindrical, long-pedicellate, with a $\mathbf{J}^{-}$, wedge-shaped, subapical ring. Ascospores fasciculate, spiral, filiform, straight or curved, hyaline or pale-yellowish in mass, aseptate, ends rounded, with or without polar mucilaginous appendages, smooth-walled. Asexual morph: Undetermined.

Notes - Leptosporella was introduced by Penzig \& Saccardo (1897) with L. gregaria Penz. \& Sacc. as the type species. This genus was placed in the subclass Sordariomycetidae, genera incertae sedis by Lumbsch \& Huhndorf (2010) and the holotype and fresh specimens were examined by Huhndorf \& Miller (2011). Based on the phylogenetic analyses of LSU sequence data, Leptosporella was transferred to the Chaetosphaeriales (Huhndorf \& Miller 2011). Maharachchikumbura et al. (2015) did not assign Leptosporella to any families in Sordariomycetes. Dai et al. (2016) introduced a new species, L. bambusae, from bamboo and based on LSU and ITS 


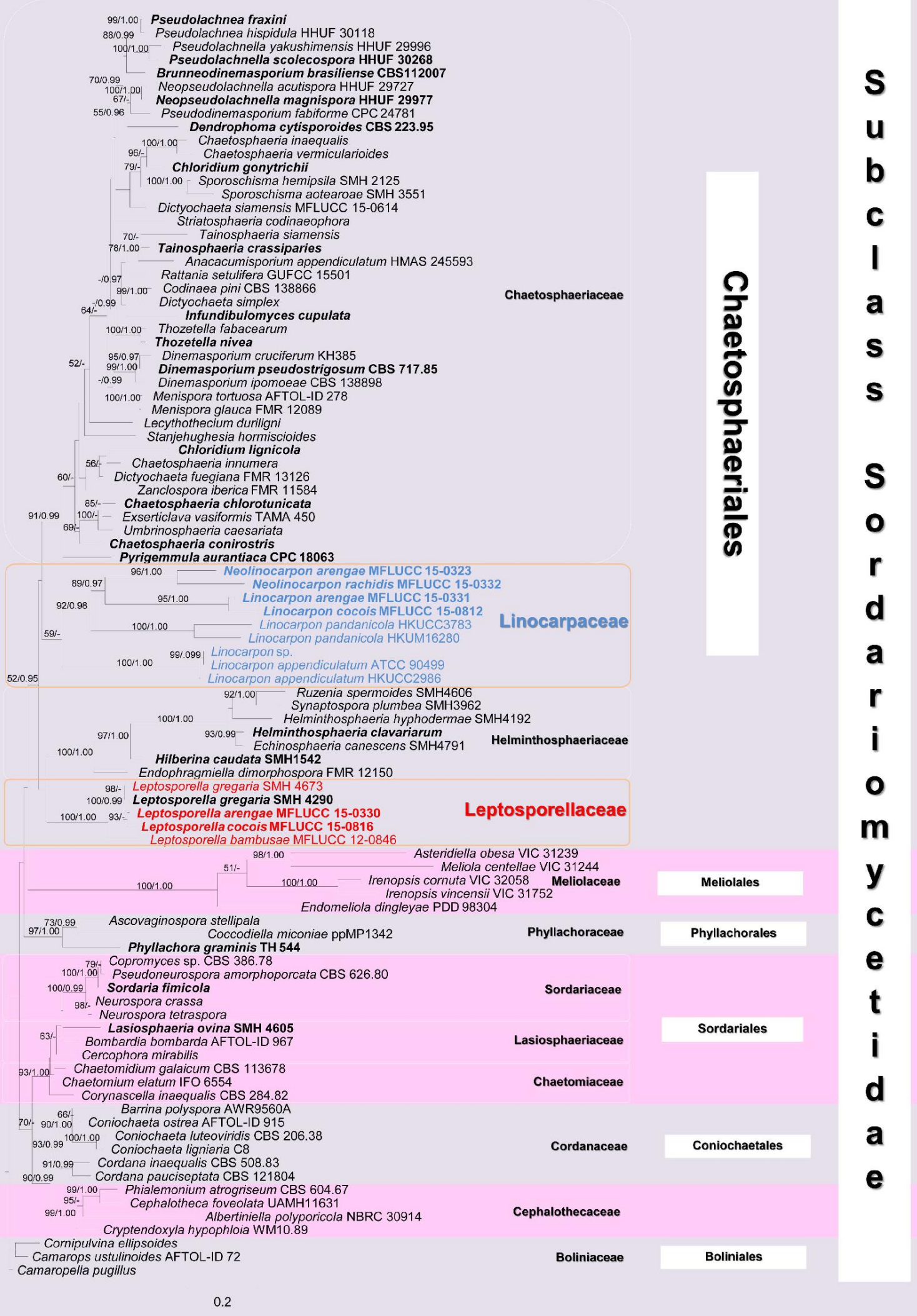

Figure 1 The parsimonious trees resulting from maximum likelihood (ML) analysis of a combined ITS and LSU dataset of species in the subclass Sordariomycetidae. Maximum likelihood (ML) bootstrap values $\geq 50 \%$. Bayesian posterior probabilities (BYPP) greater than 0.95 is given at the nodes. The ex-type strains are in bold. The new family Linocarpaceae and new strains are in blue. The new family Leptosporellaceae and new strains are in red. 
Table 2 GenBank accession numbers of the sequences used in phylogenetic analysis.

\begin{tabular}{|c|c|c|c|}
\hline \multirow{2}{*}{ Species name } & \multirow{2}{*}{ Strains } & \multicolumn{2}{|c|}{ GenBank accession numbers } \\
\hline & & LSU & ITS \\
\hline Albertiniella polyporicola & NBRC 30914 & AB178271 & AB278196 \\
\hline Anacacumisporium appendiculatum & HMAS 245593 & KT001553 & KT001555 \\
\hline Ascovaginospora stellipala & - & U85088 & - \\
\hline Asteridiella obesa & VIC31239 & JX096809 & KC252608 \\
\hline Barrina polyspora & AWR9560A & AY346261 & - \\
\hline Bombardia bombarda & AFTOL-ID 967 & DQ470970 & - \\
\hline Brunneodinemasporium brasiliense & CBS 112007 & JQ889288 & JQ889272 \\
\hline Camaropella pugillus & - & EU481406 & - \\
\hline Camarops ustulinoides & AFTOL-ID 72 & DQ470941 & - \\
\hline Cephalotheca foveolata & UAMH11631 & KC408398 & KC408422 \\
\hline Cercophora mirabilis & SMH 4002 & - & KX171945 \\
\hline Chaetomidium galaicum & CBS113678 & FJ666361 & JN573175 \\
\hline Chaetomium elatum & IFO 6554 & DQ368628 & - \\
\hline Chaetosphaeria chlorotunicata & SMH 1565 & AF466064 & - \\
\hline Chaetosphaeria conirostris & SMH 2183 & AF466066 & - \\
\hline Chaetosphaeria inaequalis & - & - & AF178564 \\
\hline Chaetosphaeria vermicularioides & MR 1148 & - & AF178550 \\
\hline $\begin{array}{l}\text { Chloridium } \\
\text { gonytrichii" }\end{array}$ gonytrichii $=$ "Melanopsammella & SMH 3785 & AF466085 & - \\
\hline Chloridium lignicola & CBS 143.54 & AF178544 & AF178544 \\
\hline Coccodiella miconiae & ppMP1342 & KX430506 & - \\
\hline Codinaea pini & CBS 138866 & KР004493 & KP004465 \\
\hline Coniochaeta ligniaria & $\mathrm{C} 8$ & AY198388 & AY198390 \\
\hline Coniochaeta luteoviridis & CBS 206.38 & AF353603 & - \\
\hline Coniochaeta ostrea & AFTOL-ID 915 & DQ470959 & - \\
\hline Copromyces sp. & CBS 386.78 & AY346277 & - \\
\hline Cordana inaequalis & CBS 508.83 & HE672157 & HE672146 \\
\hline Cordana pauciseptata & CBS: 121804 & HE672160 & HE672149 \\
\hline Corynascella inaequalis & CBS 284.82 & - & HQ871763 \\
\hline Dendrophoma cytisporoides & CBS 223.95 & JQ889289 & JQ889273 \\
\hline Dictyochaeta fuegiana & FMR_13126 & KY853500 & KY853440 \\
\hline Dictyochaeta siamensis & MFLŪCC 15-0614 & KX609952 & KX609955 \\
\hline Dictyochaeta simplex & ICMP 14613 & - & EF029193 \\
\hline Dinemasporium cruciferum & КH385 & - & AB900896 \\
\hline Dinemasporium ipomoeae & CBS 138898 & KP004474 & KP004446 \\
\hline Dinemasporium pseudostrigosum & CBS 717.85 & JQ889294 & JQ889278 \\
\hline Echinosphaeria canescens & SMH4791 & AY436403 & - \\
\hline Endomeliola dingleyae & PDD98304 & GU138866 & GU138865 \\
\hline Endophragmiella dimorphospora & FMR_12150 & KY853502 & KY853442 \\
\hline Exserticlava vasiformis & TAMA 450 & AB753846 & - \\
\hline Helminthosphaeria clavariarum & - & AY346283 & - \\
\hline Helminthosphaeria hyphodermae & SMH4192 & KF765608 & - \\
\hline Hilberina caudata & SMH1542 & KF765615 & - \\
\hline Irenopsis cornuta & VIC32058 & KC618642 & - \\
\hline Irenopsis vincensii & VIC31752 & JX096807 & KC252607 \\
\hline Infundibulomyces cupulata & - & EF113979 & EF113976 \\
\hline Lasiosphaeria ovina & SMH4605 & AY436413 & AY587923 \\
\hline Lecythothecium duriligni & - & AF261071 & - \\
\hline Leptosporella arengae & MFLUCC 15-0330 & MG272246 & MG272255 \\
\hline Leptosporella bambusae & MFLUCC 12-0846 & KU863122 & KU940134 \\
\hline Leptosporella cocois & MFLUCC 15-0816 & - & MG272256 \\
\hline Leptosporella gregaria & SMH 4290 & AY346290 & - \\
\hline Leptosporella gregaria & SMH 4673 & HM171287 & - \\
\hline Linocarpon appendiculatum & ATCC 90499 & AY346291 & - \\
\hline Linocarpon appendiculatum & HKUCC2986 & DQ810199 & - \\
\hline Linocarpon arengae & MFLUCC 15-0331 & MG272247 & - \\
\hline Linocarpon cocois & MFLUCC 15-0812 & MG272248 & MG272257 \\
\hline Linocarpon pandanicola & HKUCC3783 & DQ810210 & - \\
\hline
\end{tabular}


Table 2 Continued.

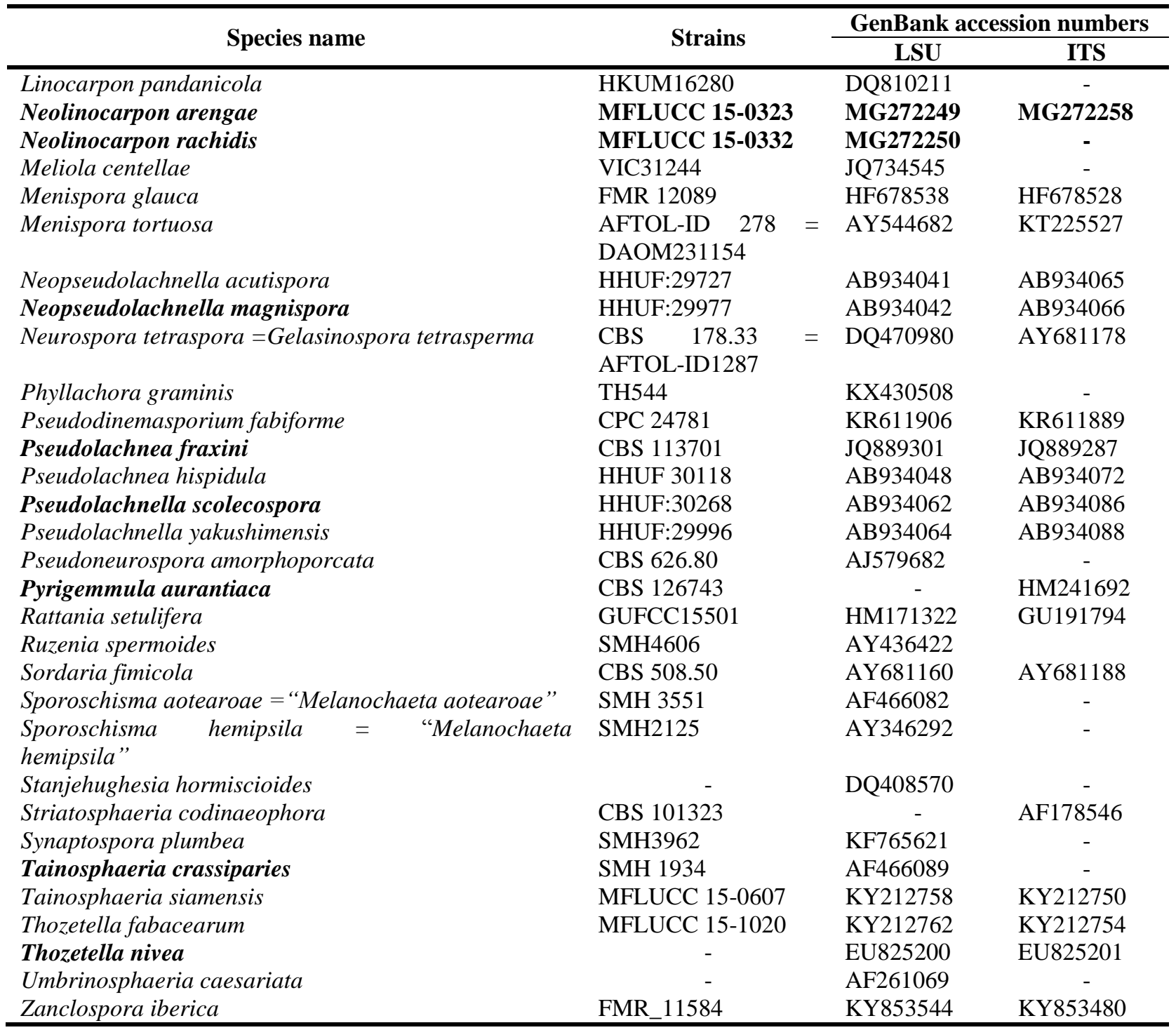

sequence data and placed Leptosporella as Chaetosphaeriales incertae sedis. In this study we formally establish Leptosporella in Leptosporellaceae fam. nov. (Chaetosphaeriales). Presently 12 species epithets are included Leptosporella in Index Fungorum (2017). The ascospores in species of Leptosporella are narrowly, long filiform, with gradually tapering ends and if mucilage is present it is indistinct. In Linocapon and Neolinocarpon species ascospores have a distinct appendage at the apex and are generally wider and differ in appearance at the ends.

Leptosporella arengae Konta \& K.D. Hyde, sp. nov.

Fig. 2

Index Fungorum number: IF553957; Facesoffungi number: FoF03841

Etymology - The specific epithet refers to the host genus Arenga

Holotype - MFLU 15-0305

Saprobic on rachis of Arenga pinnata (Wurmb) Merr. Sexual morph: Ascomata 582-928 $\mu \mathrm{m}$ diameter $\times 293-354 \mu \mathrm{m}$ high $(\bar{x}=777 \times 333 \mu \mathrm{m}, \mathrm{n}=10)$, solitary, superficial, comprising black, carbonaceous, dome-shaped, raised blister-like areas, subglobose, flattened at the base, ostiole central. Peridium 78-150 $\mu \mathrm{m}$ diameter $(\bar{x}=104 \mu \mathrm{m}, \mathrm{n}=10)$, outer cells merging with the host epidermal cells, composed of dark brown to black cells of textura angularis. Hamathecium comprising numerous, 1.5-3 $\mu \mathrm{m}$ diameter $(\bar{x}=2 \mu \mathrm{m}, \mathrm{n}=10)$, hyaline, hypha-like, septate paraphyses, longer than asci. Asci 137-190 × 10-14 $\mu \mathrm{m}(\bar{x}=160 \times 12 \mu \mathrm{m}, \mathrm{n}=20)$, 8-spored, unitunicate, cylindrical, long-pedicellate, with a $\mathrm{J}^{-}$, wedge-shaped, subapical ring. Ascospores 108 
$132 \times 2-3.5 \mu \mathrm{m}(\bar{x}=122 \times 3 \mu \mathrm{m}, \mathrm{n}=20)$, fasciculate, spiral, filiform, straight or curved, C-shaped or sigmoid, hyaline or pale-yellowish in mass, aseptate, ends rounded, with polar mucilaginous appendages, smooth-walled. Asexual morph: Undetermined.
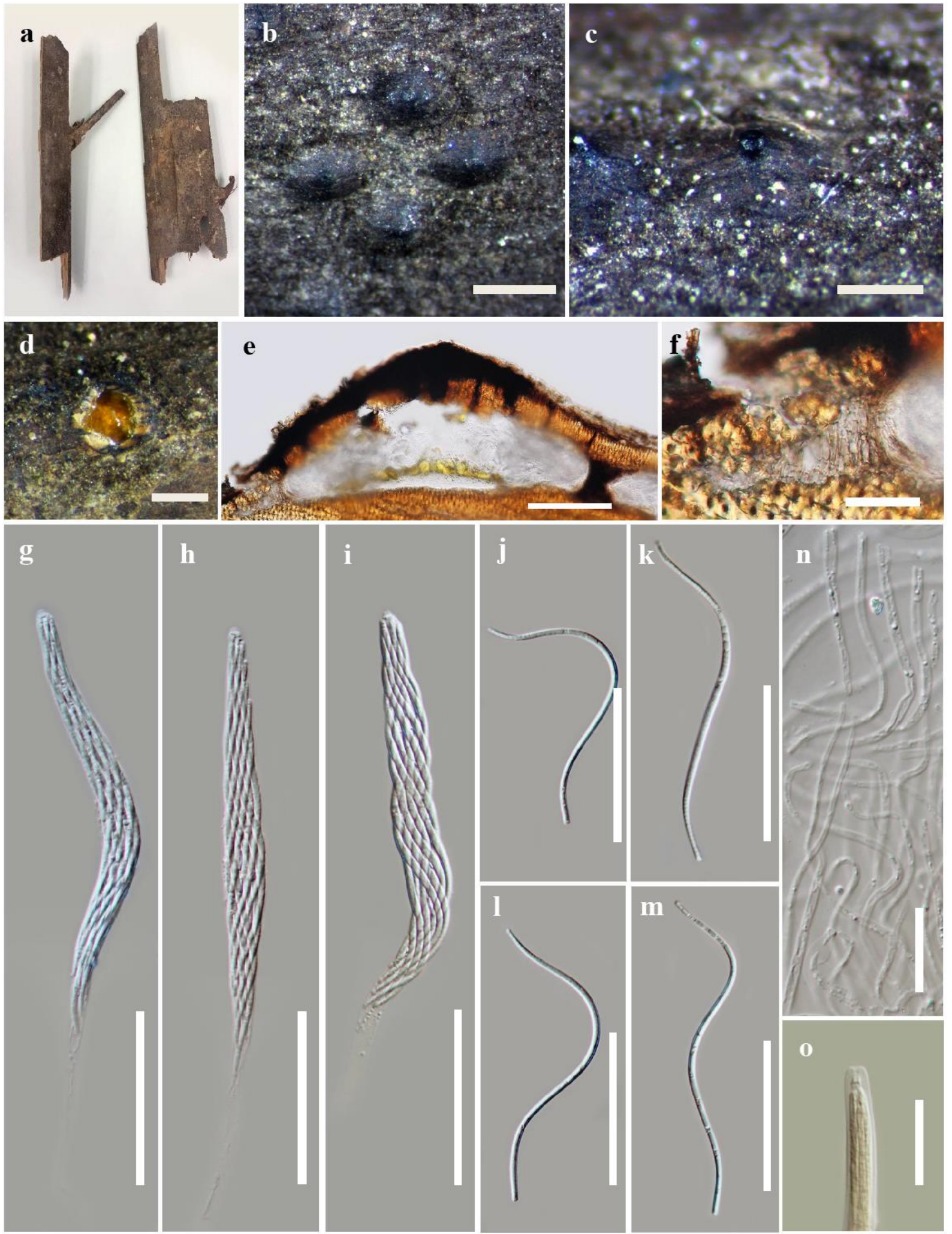

Figure 2 - Leptosporella arengae (MFLU 15-0305, holotype). a Appearance of ascomata on host substrate. b, c Close up of ascomata. d Yellowish ascospore mass. e Section of ascoma. f Peridium. $\mathrm{g}-\mathrm{i}$ Asci. $\mathrm{j}-\mathrm{m}$ Ascospores. $\mathrm{n}$ Paraphyses. o J- reaction of apical ring. Scale bars: $\mathrm{b}=1,000 \mu \mathrm{m}, \mathrm{c}-\mathrm{d}$ $=500 \mu \mathrm{m}, \mathrm{e}=200 \mu \mathrm{m}, \mathrm{f}-\mathrm{m}=50 \mu \mathrm{m}, \mathrm{n}-\mathrm{o}=20 \mu \mathrm{m}$. 
Culture characters - Ascospores germinating on MEA within 3 days. Colonies on MEA reaching 6-7.5 $\mathrm{cm}$ diameter after two months at $25^{\circ} \mathrm{C}$, white at the edge, brown in the center with strong radiations outwards, after 30 days of incubation, colonies smooth-walled, flat, margin lobate, white at the center and become brown at the margin, hyphae, septate, branched and smooth-walled.

Material examined - THAILAND, Phang-Nga Province, on dead rachis of Arenga pinnata (Wurmb) Merr. (Arecaceae), 5 December 2014, Sirinapa Konta PHR07a (MFLU 15-0305, holotype); HKAS100704, isotype; ex-type living culture, MFLUCC 15-0330.

GenBank numbers - SSU: MG366594; TEF: MG272259; RPB2: MG272260

Notes - Leptosporella arengae is introduced as a new species based on its unique morphology and phylogeny. It differs from other species in Leptosporella in having cylindrical, long pedicellate, thin-walled asci and spiral, filiform, straight or curved, C-shaped or sigmoid ascospores with polar mucilaginous appendage at the apex (Table 1). However, it shares similarity with other species, it has solitary, superficial, carbonaceous, dome-shaped ascomata, asci with J-, subapical ring, and hyaline ascospores. Phylogenetic analysis indicates that Leptosporella arengae clusters with L. cocois (93\% BS), but differs in having smaller ascomata, asci, ascospores, aseptate with a mucilaginous appendage ascospores, while L. cocois has larger ascomata, paraphyses, asci, ascospores without mucilaginous appendage, and 2-4-septate when ascospore geminated. Sequence data are available only for L. gregaria and L. bambusae, and with two unidentified strains.

Leptosporella cocois Konta \& K.D. Hyde, sp. nov.

Fig. 3

Index Fungorum number: IF553958; Facesoffungi number: FoF 03842

Etymology - The specific epithet refers to the host genus cocos

Holotype - MFLU 15-2349

Saprobic on rachis of Cocos nucifera L. Sexual morph: Ascomata 705-977 $\mu \mathrm{m}$ diameter $\times$ 209-298 $\mu \mathrm{m}$ high $(\bar{x}=800 \times 250 \mu \mathrm{m}, \mathrm{n}=10)$, solitary or aggregated, superficial, comprising black, dome shaped, raised blistering areas, subglobose, flattened at the base, ostiole central. Peridium 76-125 $\mu \mathrm{m}$ diameter $(\bar{x}=98 \mu \mathrm{m}, \mathrm{n}=10)$, outer cells merging with the host epidermal cells, composed of dark brown to black cells of textura angularis. Hamathecium comprising numerous, 3-6 $\mu \mathrm{m}$ diameter $(\bar{x}=4.5 \mu \mathrm{m}, \mathrm{n}=10)$, hypha-like, septate paraphyses, longer than asci. Asci 145-242 × 8-13 $\mu \mathrm{m}(\bar{x}=187 \times 10 \mu \mathrm{m}, \mathrm{n}=20), 8$-spored, unitunicate, cylindrical, longpedicellate, with a J-, wedge-shaped, subapical ring. Ascospores $99-156 \times 2.5-4 \mu \mathrm{m}(\bar{x}=126 \times 3$ $\mu \mathrm{m}, \mathrm{n}=20$ ), fasciculate, becoming spiral when mature, filiform, straight or curved, hyaline, aseptate, rounded at the apex, pointed at the base, smooth-walled, 1-4-septate when geminated. Asexual morph: Undetermined.

Culture characters - Ascospores germinating on MEA within 2 days. Colonies on MEA growing, reaching 7-8.5 cm diameter after 2 months at $25^{\circ} \mathrm{C}$, white at the edge, brown in the center, outwardly with strong light brown radiations. After 30 days of incubation, colonies smooth, flat, margin entire, hypha septate, branched and smooth-walled.

Material examined - THAILAND, Prachaupkhirikan Province, Sai Khu Water Fall, on dead rachis of Cocos nucifera L. (Arecaceae), 30 July 2015, Sirinapa Konta PJK04k (MFLU 15-2349, holotype, HKAS 100705, isotype; ex-type living culture, MFLUCC 15-0816).

Notes - The phylogenetic analyses indicate that Leptosporella cocois is closely related to $L$. arengae, but they differ in the features of ascomata, asci, ascospores and paraphyses (Figs. 1, 2 and 3). Morphological differences are discussed under the latter species. Leptosporella cocois differs from L. gregaria (type species) in having larger asci with long pedicels, and filiform aseptate ascospores, while L. gregaria has smaller asci and ascospores than L. cocois, short pedicellate asci, and 7-septate ascospores. Leptosporella cocois is distinct from $L$. arengae in having larger ascomata, asci and ascospores without mucilaginous appendages, while L. arengae has smaller ascomata, asci and aseptate ascospores, lacking mucilaginous appendages and it differs from $L$. macrothecea, L. sparsa, and L. bambusae in having filiform ascospores, while L. macrothecea and $L$. sparsa have fusoid ascospores and $L$. bambusae has long fusiform ascospores (Table 1). 


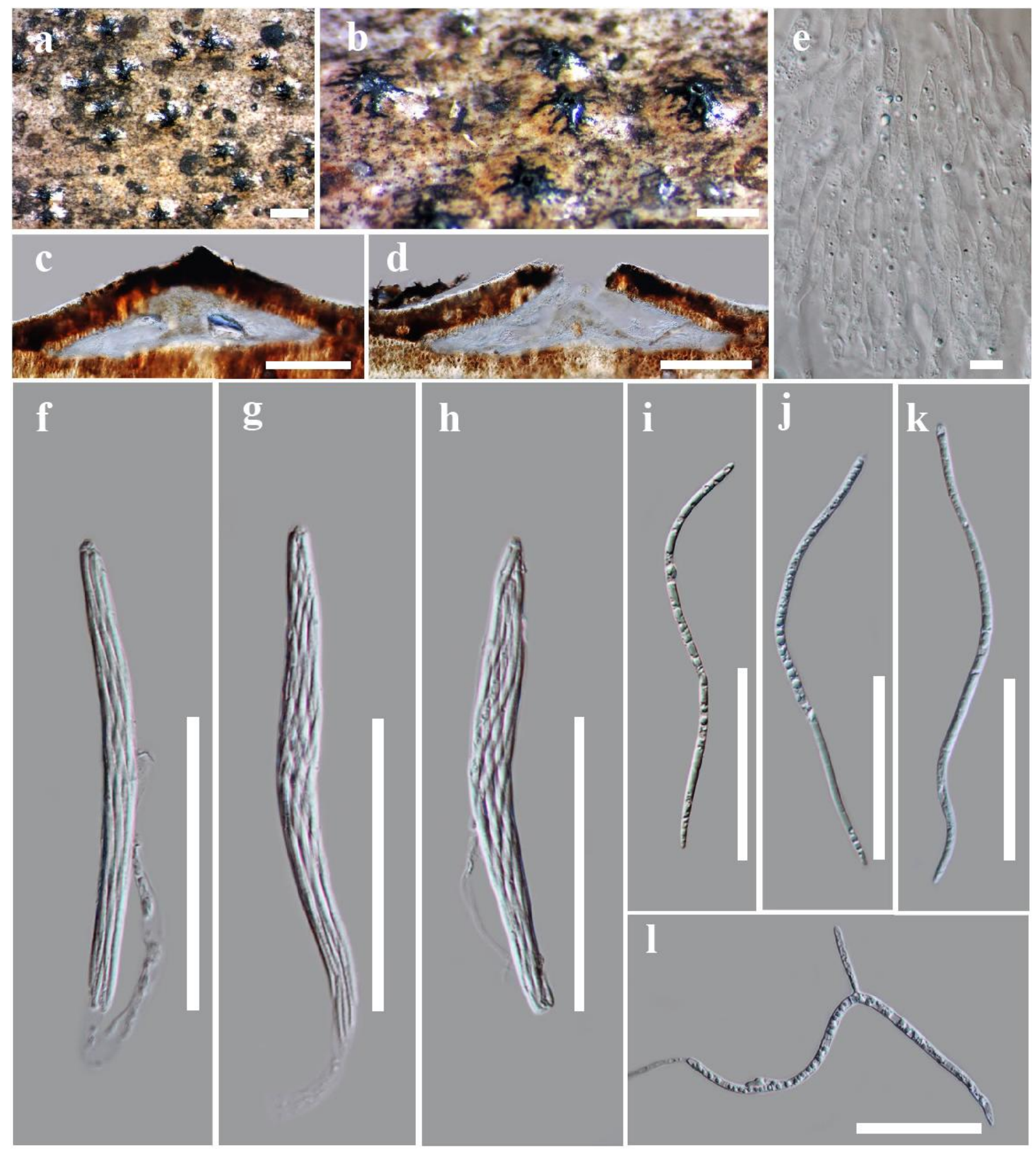

Figure 3 - Leptosporella cocois (MFLU 15-2349, holotype). a Appearance of ascomata on host substrate. b Close up of ascomata. c-d Sections of ascomata. e Paraphyses. $\mathrm{f}-\mathrm{h}$ Asci. i-k Ascospores. 1 Germinated ascospore. Scale bars: $\mathrm{a}=1,000 \mu \mathrm{m}, \mathrm{b}=500 \mu \mathrm{m}, \mathrm{c}-\mathrm{d}=200 \mu \mathrm{m}, \mathrm{e}=10$ $\mu \mathrm{m}, \mathrm{f}-\mathrm{k}=50 \mu \mathrm{m}, \mathrm{l}=20 \mu \mathrm{m}$.

Linocarpaceae Konta \& K.D. Hyde, fam. nov.

Index Fungorum number: IF553959; Facesoffungi number: FoF03843

Saprobic on monocotyledon and dicotyledons. Sexual morph: Ascomata solitary, superficial comprising black, dome-shaped (Linocarpon), slightly raised or flattened circular areas, or immersed (Neolinocarpon) with a black shiny papilla. Peridium composed of dark brown to black cells of textura angularis. Hamathecium of septate paraphyses, longer than asci, wider at the base, tapering towards the apex. Asci 8-spored, unitunicate, cylindrical, with a $\mathrm{J}^{-}$an apical ring, developing from the base and periphery of the ascomata. Ascospores parallel or spiral in asci, filiform, straight or curved, hyaline or pale-yellowish in mass, unicellular with refringent bands, 
with or without polar appendages. Asexual morph: A phialophora-like spp. was found in Linocarpon appendiculatum and L. elaeidis cultures (Hyde 1992a), but has not been recovered in other species.

Notes - The species belongs in Linocarpaceae are saprobes on monocotyledons and dicotyledons plants. Characteristic of species of Linocarpaceae was mentioned above and phylogenetic analysis indicates that Linocarpaceae forms a distinct clade sister to Chaetosphaeriaceae (Fig. 1). Thus, Linocarpaceae is introduced as a new family in Chaetosphaeriales (Sordariomycetidae) based on morphology and phylogeny.

Type genus - Linocarpon Syd. \& P. Syd., Annls mycol. 15(3/4): 210 (1917)

Linocarpon Syd. \& P. Syd., Annls mycol. 15(3/4): 210 (1917)

Saprobic on monocotyledon and dicotyledon plants. Sexual morph: Ascomata solitary, superficial, comprising black, dome-shaped, raised blistering areas, subglobose, flattened at the base, with a central ostiole. Peridium outer cells merging with the host epidermal cells, composed of dark brown to black cells of textura angularis. Hamathecium comprising hyaline, septate paraphyses, longer than asci, wider at the base, tapering towards the apex. Asci 8-spored, cylindrical, unitunicate, apically rounded, with a small non amyloid apical ring, developing from the base and periphery of the ascomata. Ascospores filiform, hyaline or pale-yellowish in mass, parallel or spiral in the ascus, ends rounded, inflated, appendage or acute, containing numerous refringent septum-like bands (Syd \& Syd 1917, Hyde 1992a). Asexual morph: Phialophora-like spp. was found in Linocarpon appendiculatum and L. elaeidis cultures but never reported in other species.

Notes - Linocarpon was introduced by Sydow \& Sydow (1917), monographed by Hyde (1992a), and updated by Hyde (1997), Dulymamode et al. (1998), Hyde \& Alias (1999), Fröhlich \& Hyde (2000), Thongkantha et al. (2003) and Cai et al. (2004). Linocarpon species have ascomata on the host surface that form black, dome-shaped, raised blistering areas, with a central ostiole. Asci are unitunicate, cylindrical with a small non-amyloid apical ring. Ascospores are filiform and aseptate (Fröhlich \& Hyde 2000, Poonyth et al. 2000). The distinct ascospore appendage at the apex is important to differentiate Linocarpon and Neolinocarpon from Leptosporella as well as distinguish between species (Poonyth et al. 2000, Yanna \& Hyde 2003, Cai et al. 2004). The Phialophora asexual morph of Linocarpon is rarely observed (Hyde 1992a). Fourty-one records of Linocarpon are listed in Index Fungorum 2017 and DNA sequence data are available for 33 sequences in GenBank (16 November 2017).

Linocarpon arengae Konta \& K.D. Hyde, sp. nov.

Index Fungorum number: IF553960; Facesoffungi number: FoF03844

Etymology - The specific epithet refers to the host genus Arenga.

Holotype: MFLU: 15-0306.

Saprobic on rachis of Arenga pinnata (Wurmb) Merr. Sexual morph: Ascomata 125-355 $\mu \mathrm{m}$ high $\times 878-1,368 \mu \mathrm{m}$ diameter $(\bar{x}=205 \times 1,094 \mu \mathrm{m}, \mathrm{n}=10)$, solitary or aggregated, superficial, comprising black, dome-shaped, raised, blistering areas, subglobose, flattened at the base, with a central ostiole. Peridium 64-90 $\mu \mathrm{m}$ diameter $(\bar{x}=76 \mu \mathrm{m}, \mathrm{n}=10)$, outer cells merging with the host epidermal cells, composed of dark brown to black cells of textura angularis. Hamathecium comprising numerous, 2-3.5 $\mu \mathrm{m}$ diameter $(\bar{x}=3 \mu \mathrm{m}, \mathrm{n}=10)$, hyaline, hypha-like, septate paraphyses, longer than asci. Asci $132-177 \times 9-15 \mu \mathrm{m}(\bar{x}=153 \times 11 \mu \mathrm{m}, \mathrm{n}=20)$, 8-spored, unitunicate, cylindrical, long-pedicellate, with a $\mathrm{J}^{-}$, wedge-shaped, subapical ring. Ascospores $91-$ $102 \times 2-4 \mu \mathrm{m}(\bar{x}=102 \times 3 \mu \mathrm{m}, \mathrm{n}=20)$, parallel when immature, becoming spiral when mature, filiform, straight or curved, hyaline, aseptate, containing numerous refringent septum-like bands, ends rounded, with polar mucilaginous appendage at the apex, smooth-walled. Asexual morph: Undetermined. 


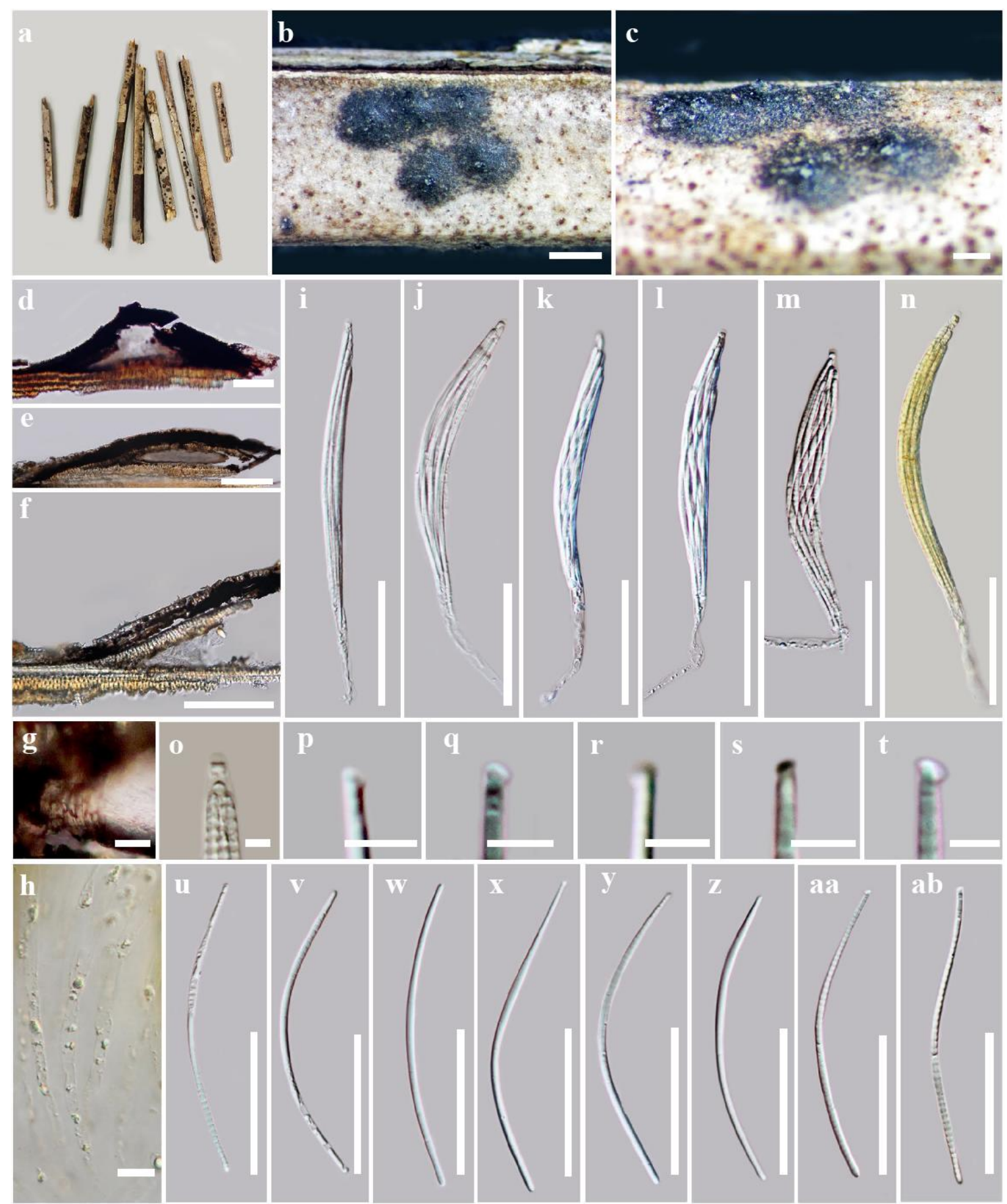

Figure 4 - Linocarpon arengae (MFLU 15-0306, holotype). a Appearance of ascomata on host substrate. b, c Close up of ascoma. d Yellowish ascospore mass. e Section of ascomata. f, g Peridium. $\mathrm{h}$ Paraphyses. $\mathrm{i}-\mathrm{n}$ asci. o J- reaction of apical ring. $\mathrm{p}-\mathrm{t}$ Appendage. $\mathrm{u}-\mathrm{ab}$ Ascospores. Scale bars: $\mathrm{b}=500 \mu \mathrm{m}, \mathrm{c}-\mathrm{f}=200 \mu \mathrm{m}, \mathrm{g}=20 \mu \mathrm{m}, \mathrm{h}=10 \mu \mathrm{m}, \mathrm{i}-\mathrm{n}, \mathrm{u}-\mathrm{ab}=50 \mu \mathrm{m}$, and $\mathrm{o}-\mathrm{t}=5 \mu \mathrm{m}$.

Culture characters - Ascospores germinating on MEA within 3 days. Colonies on MEA reaching 6.5-7 cm diameter after 2 months at $25^{\circ} \mathrm{C}$, white at the edge, brown in the middle with strong radiations outwards. After 30 days of incubation, colonies smooth, hyphae septate, branched, smooth.

Material examined - THAILAND, Phang-Nga Province, on dead rachis of Arenga pinnata (Wurmb) Merr. (Arecaceae), 5 December 2014, Sirinapa Konta PHR07h (MFLU 15-0306, holotype); HKAS100700, isotype; ex-type living culture, MFLUCC 15-0331.

GenBank number - SSU: MG366596 
Notes - Linocarpon arengae is introduced as a new species based on the morphology and DNA sequence data. However, the species that was included in this genus is known form a polyphyletic clade based on LSU sequence data (Bahl 2006). Furthermore, in this study the phylogenetic analyses indicated that $L$. arengae is most closely related to L. cocois with good bootstrap support and was placed in the same clade with $L$. pandanicola and shown as a monophyletic clade within Linocarpaceae fam. nov., but it forms a distinct lineage (Table 1).

Linocarpon cocois Konta \& K.D. Hyde, sp. nov.

Fig. 5

Index Fungorum number: IF553961; Facesoffungi number: FoF 03845

Etymology - The specific epithet refers to the host genus Cocos

Holotype: MFLU 15-2345

Saprobic on rachis of Cocos nucifera L. Sexual morph: Ascomata 73-184 $\mu \mathrm{m}$ high $\times 400-980$ $\mu \mathrm{m}$ diameter $(\bar{x}=124 \times 655 \mu \mathrm{m}, \mathrm{n}=10$, up to $1,000 \mu \mathrm{m})$, solitary or aggregated, superficial, comprising shiny, black, dome shaped, raised blistering areas, subglobose, flattened at the base, central ostiole. Peridium 60-92 $\mu \mathrm{m}$ diameter $(\bar{x}=71 \mu \mathrm{m}, \mathrm{n}=10)$, outer cells merging with the host epidermal cells, composed of dark brown to black, cells of textura angularis. Hamathecium comprising numerous, 0.5-1 $\mu \mathrm{m}$ diameter $(\bar{x}=0.7 \mu \mathrm{m}, \mathrm{n}=10)$, hyaline, septate, hypha-like paraphyses, longer than asci. Asci $100-153 \mu \mathrm{m} \times 8-15 \mu \mathrm{m}(\bar{x}=120 \times 10 \mu \mathrm{m}, \mathrm{n}=20)$, 8-spored, unitunicate, cylindrical, long-pedicellate, with a J-, wedge-shaped, subapical ring. Ascospores 69$90 \times 3-5 \mu \mathrm{m}(\bar{x}=76 \times 4 \mu \mathrm{m}, \mathrm{n}=20)$, parallel when immature, becoming spiral at maturity, filiform-fusiform, straight or curved, hyaline, aseptate when mature, becoming multi-septate when germinating, without refringent septum-like bands, ends rounded, the base wider than apex, smooth-walled, with a mucilaginous appendage at the apex, producing germ tube from each cell. Asexual morph: Undetermined.

Culture characters - Ascospores germinating on MEA within 24 hours. Colonies on MEA reaching 7-8.5 cm diameter after 2 months at $25^{\circ} \mathrm{C}$, white at the edge with strong radiations outwards. After 30 days of incubation, colonies smooth, flat, entire edge margin, brown, hyphae septate, branched, smooth.

Material examined - THAILAND, Prachaupkhirikan Province, Sai Khu Water Fall, on dead rachis of Cocos nucifera L. (Arecaceae), 30 July 2015, Sirinapa Konta PJK04f (MFLU 15-2345, holotype); HKAS100701, isotype; ex-type living culture, MFLUCC 15-0812.

Notes - Linocarpon cocois is morphologically similar to Linocarpon genus in its black, dome-shaped, raised blistering areas, flattened at the base, with a central ostiole. Phylogenetically $L$. cocois groups together with $L$. arengae (Fig. 1). In addition our $L$. cocois isolate has been collected from the same family host (Arecaceae) with $L$. arengae but has been collected from Cocos nucifera and Arenga pinnata. Linocarpon pandanicola, on the other hand, has been isolated from Pandanaceae. Although L. cocois is closely related to L. arengae, it differs in having ascospore shape, size, lack the refringent septum-like bands and differ in the shape and the type of appendages.

\section{Neolinocarpon K.D. Hyde 1992}

Saprobic on mostly monocotyledons. Sexual morph: Ascomata solitary, deeply immersed, oval to globose, with central raised, dark, shiny papilla, ostiole with periphyses, ascospores paleyellowish in mass. Peridium outer cells merging with the host epidermal cells, composed of dark brown to black cells of textura angularis. Hamathecium comprising tapering, septate paraphyses, longer than asci. Asci 8-spored, unitunicate, long cylindrical, pedicelate, apex rounded, containing an oblong to wedge-shaped, refractive, apical ring, and some with a refractive circular body below. Ascospores filiform, straight or curved, hyaline, 1-celled, with refringent bands, with apical appendages (Hyde 1992b). Asexual morph: Undetermined.

Notes - Neolinocarpon was introduced by Hyde (1992b) and typified by N. globosicarpum K.D. Hyde. This genus was placed in Xylariaceae based on morphology (Hyde 1992b). Hyde (1997) included Neolinocarpon in Hyponectriaceae. Wang \& Hyde (1999) excluded 
Neolinocarpon from Hyponectriaceae. Then Kirk et al. (2001) and Eriksson (2006) assigned Neolinocarpon into Sordariomycetes incertae sedis. Bahl (2006) re-examined the utilized fresh samples and dried herbarium material. Based on the phylogenetic analysis of LSU and RPB2 DNA sequence data, Neolinocarpon was not monophyletic clade and transferred into Xylariales and Chaetosphaeriales (Bahl 2006). Maharachchikumbura et al. (2015) did not determine the family placement of Neolinocarpon in their studies.Vitoria et al. (2013) introduced new species of Neolinocarpon attaleae from Attalea funifera (Arecaceae) based on the morphological characters. In this study Neolinocarpon is placed in Linocarpaceae (Chaetosphaeriales) based on phylogenetic analysis (Fig. 1). Ten species epithets of Neolinocarpon are listed in Index Fungorum (2017).

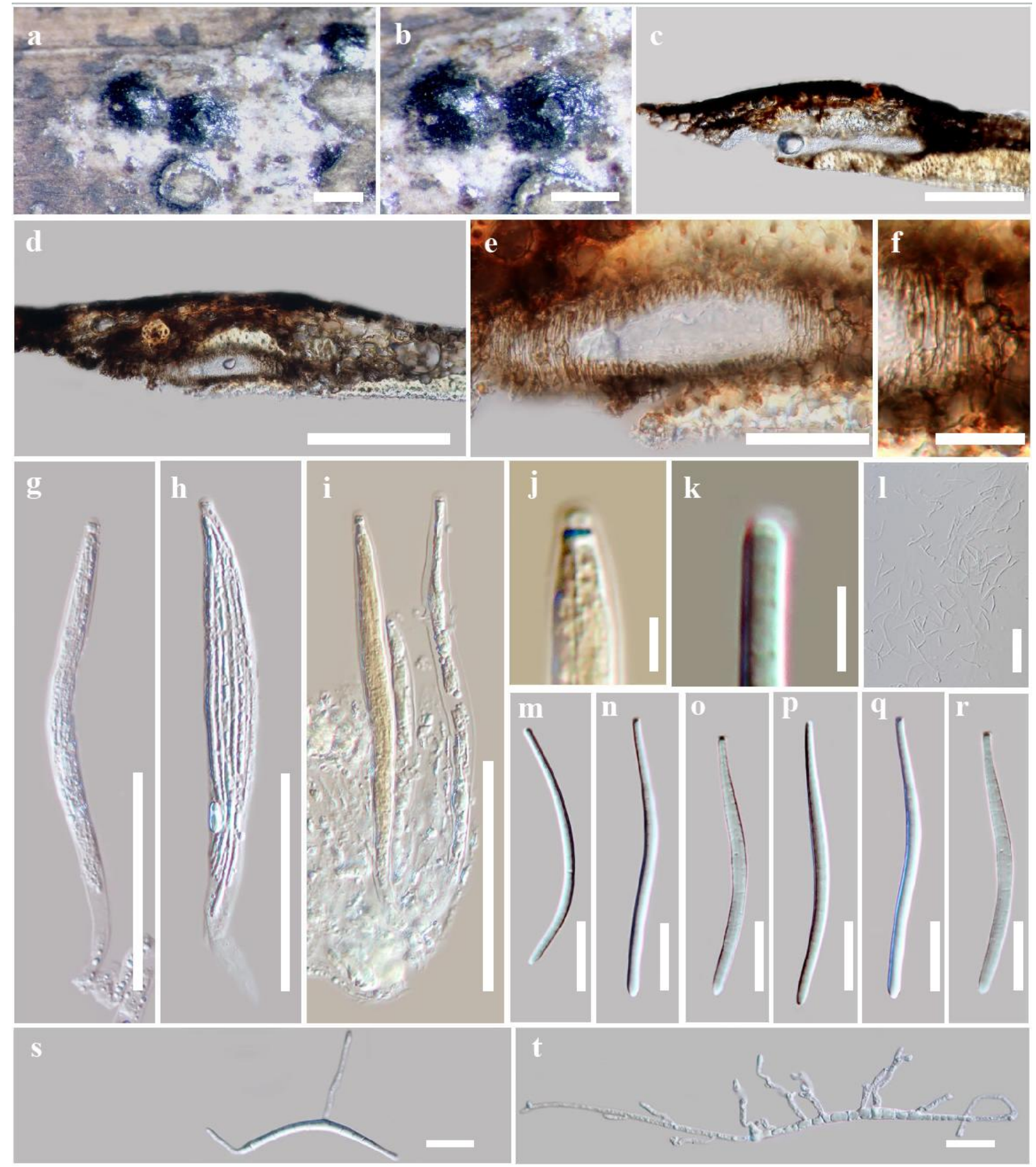

Figure 5 - Linocarpon cocois (MFLU 15-2345, holotype). a Ascomata on host substrate. b Close up of ascomata. c-e Sections of ascomata. f Peridium. g-i Asci. j J- reaction of apical ring. $\mathrm{k}$ Appendage. 1 Paraphysoids. $\mathrm{m}-\mathrm{r}$ Ascospores. $\mathrm{s}-\mathrm{t}$ Germinated ascospores. Scale bars: $\mathrm{a}, \mathrm{b}=500$ $\mu \mathrm{m}, \mathrm{c}, \mathrm{d}=200 \mu \mathrm{m}, \mathrm{e}, \mathrm{g}-\mathrm{i}=50 \mu \mathrm{m}, \mathrm{j}, \mathrm{k}=5 \mu \mathrm{m}, \mathrm{f}, \mathrm{l}-\mathrm{t}=20 \mu \mathrm{m}$ 

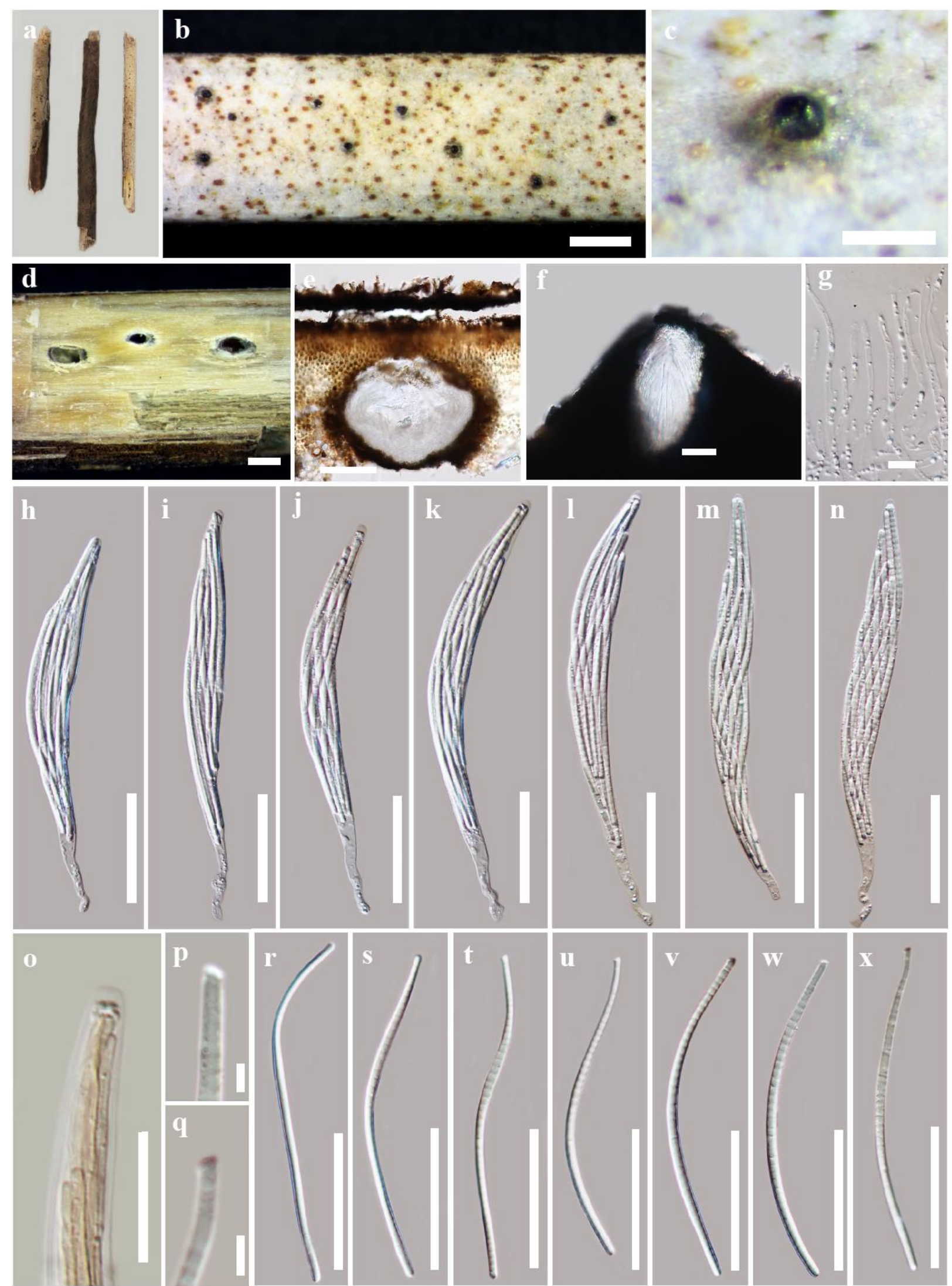

Figure 6 - Neolinocarpon arengae (MFLU 15-0298, holotype). a Appearance of ascomata on host substrate. b, c Close up of ascomata. d Yellowish ascospore mass. e Section of ascoma. f Papilla. $g$ Paraphyses. $\mathrm{h}-\mathrm{n}$ Asci. o J- reaction of apical ring. $\mathrm{p}-\mathrm{q}$ Appendages. $\mathrm{r}-\mathrm{x}$ Ascospores. Scale bars: $\mathrm{b}=$ $500 \mu \mathrm{m}, \mathrm{c}=200 \mu \mathrm{m}, \mathrm{d}=50 \mu \mathrm{m}, \mathrm{e}=200 \mu \mathrm{m}, \mathrm{g}=10 \mu \mathrm{m}, \mathrm{h}-\mathrm{n}, \mathrm{r}-\mathrm{x}=50 \mu \mathrm{m}, \mathrm{o}=20 \mu \mathrm{m}$, and $\mathrm{p}-\mathrm{q}=5$ $\mu \mathrm{m}$. 
Neolinocarpon arengae Konta \& K.D. Hyde, sp. nov.

Index Fungorum number: IF553963; Facesoffungi number: FoF03847

Etymology - The specific epithet refers to the host genus Arenga

Holotype: MFLU 15-0298

Saprobic on dead leaflet of Arenga pinnata (Wurmb) Merr. Sexual morph: Ascomata 336$566 \mu \mathrm{m}$ high $\times 230-490 \mu \mathrm{m}$ diameter $(\bar{x}=430 \times 368 \mu \mathrm{m}, \mathrm{n}=10)$, solitary, deeply immersed, with a central raised black, papilla, with a central ostiole. Papilla 129-218 $\mu \mathrm{m}$ high $\times 174-296 \mu \mathrm{m}$ diameter at the base $(\bar{x}=154 \times 203 \mu \mathrm{m}, \mathrm{n}=5)$, black, shiny, with hyaline periphyses. Peridium 33-80 $\mu \mathrm{m}$ diameter $(\bar{x}=50 \mu \mathrm{m}, \mathrm{n}=10)$, outer cells merging with the host epidermal cells, composed of dark brown to black cells of textura angularis. Hamathecium comprising numerous, 2-4 $\mu \mathrm{m}$ diameter $(\bar{x}=3 \mu \mathrm{m}, \mathrm{n}=10)$, hypha-like, septate, unbranched paraphyses, longer than asci,. Asci 168-214 × 15-21 $\mu \mathrm{m}(\bar{x}=186 \times 18 \mu \mathrm{m}, \mathrm{n}=20), 8$-spored, unitunicate, cylindrical, long-

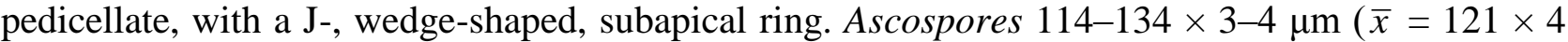
$\mu \mathrm{m}, \mathrm{n}=20$ ), parallel when immature, becoming spiral at maturity, filiform, straight or curved, hyaline, aseptate, containing numerous refringent septum-like bands, ends rounded, with polar mucilaginous appendage at apex, smooth-walled. Asexual morph: Undetermined.

Culture characters - Ascospores germinating on MEA within 2 days. Colonies on MEA reaching 6-8 cm diameter after 2 months at $25^{\circ} \mathrm{C}$, white to gray at the edge, gray to brown in the middle forward until nearly margin, light brown at margin, dark brown when mycelium growing into media 30 days of incubation, colonies smooth, flat, lobate margin, hyphae septate, branched, smooth.

Material examined - THAILAND, Phang-Nga Province, on dead leaflet of Arenga pinnata (Wurmb) Merr. (Arecaceae), 5 December 2014, Sirinapa Konta PHR07d (MFLU 15-0298, holotype); HKAS100703, isotype; ex-type living culture, MFLUCC 15-0323.

GenBank numbers -SSU: MG366597; RPB2: MG272261

Notes - Neolinocarpon arengae is similar to species of Neolinocarpon with respect to the ascomata and filiform ascospores. It however differs from some species in terms of ascomata size, ascospores shape at both ends and presence of mucilaginous appendage, and based on host differences (Table 1). Phylogenetic analysis incicated that Neolinocarpon arengae is related to $N$. rachidis (96\% ML, 1.00 PP) (Fig.1).

Neolinocarpon rachidis Konta \& K.D. Hyde, sp. nov.

Fig. 7

Index Fungorum number: IF553962; Facesoffungi number: FoF 03846

Etymology - The specific epithet refers to the host habitat (rachids).

Holotype: MFLU: 15-0307.

Saprobic on rachis of Arenga pinnata (Wurmb) Merr. Sexual morph: Ascomata 508-590 $\mu \mathrm{m}$ high $\times 320-390 \mu \mathrm{m}$ diameter $(\bar{x}=557 \times 346 \mu \mathrm{m}, \mathrm{n}=10)$, solitary, deeply immersed, with a central raised, black, globose-subglobose papilla, with a central ostiole. Papilla 157-223 $\mu \mathrm{m}$ high $\times 127-$ $198 \mu \mathrm{m}$ diameter at the base $(\bar{x}=188 \times 157 \mu \mathrm{m}, \mathrm{n}=5)$, black, shiny, with hyaline periphyses. Peridium 34-80 $\mu \mathrm{m}$ wide $(\bar{x}=55 \mu \mathrm{m}, \mathrm{n}=10)$, outer cells merging with the host epidermal cells, composed of dark brown to black cells of textura angularis. Hamathecium comprising numerous, 2.5-4 $\mu \mathrm{m}$ diameter $(\bar{x}=3 \mu \mathrm{m}, \mathrm{n}=10)$, hypha-like, septate, unbranched, paraphyses, longer than asci. Asci 157-205 × 9-19 $\mu \mathrm{m}(\bar{x}=180 \times 14 \mu \mathrm{m}, \mathrm{n}=20), 8$-spored, unitunicate, cylindrical, longpedicellate, with a wedge-shaped, J-, subapical ring. Ascospores $123-140 \times 2-4 \mu \mathrm{m}(\bar{x}=133 \times 3$ $\mu \mathrm{m}, \mathrm{n}=20$ ), parallel in ascus, becoming spiral when mature, filiform, straight or curved, hyaline, aseptate, containing numerous refringent septum-like bands, rounded at the apex with appendage, pointed at the base, smooth-walled. Asexual morph: Undetermined.

Culture characters - Ascospores germinating on MEA within 7 days. Colonies on MEA reaching 3-4 cm diameter after two months at $25^{\circ} \mathrm{C}$, white at the edge, brown in the middle with strong radiations outwards. After 30 days of incubation, colonies smooth, flat, margin undulate, white to gray in the center, gray-brown at the margin, mycelium becoming dark brown when growing into media, hyphae septate, branched, smooth-walled. 


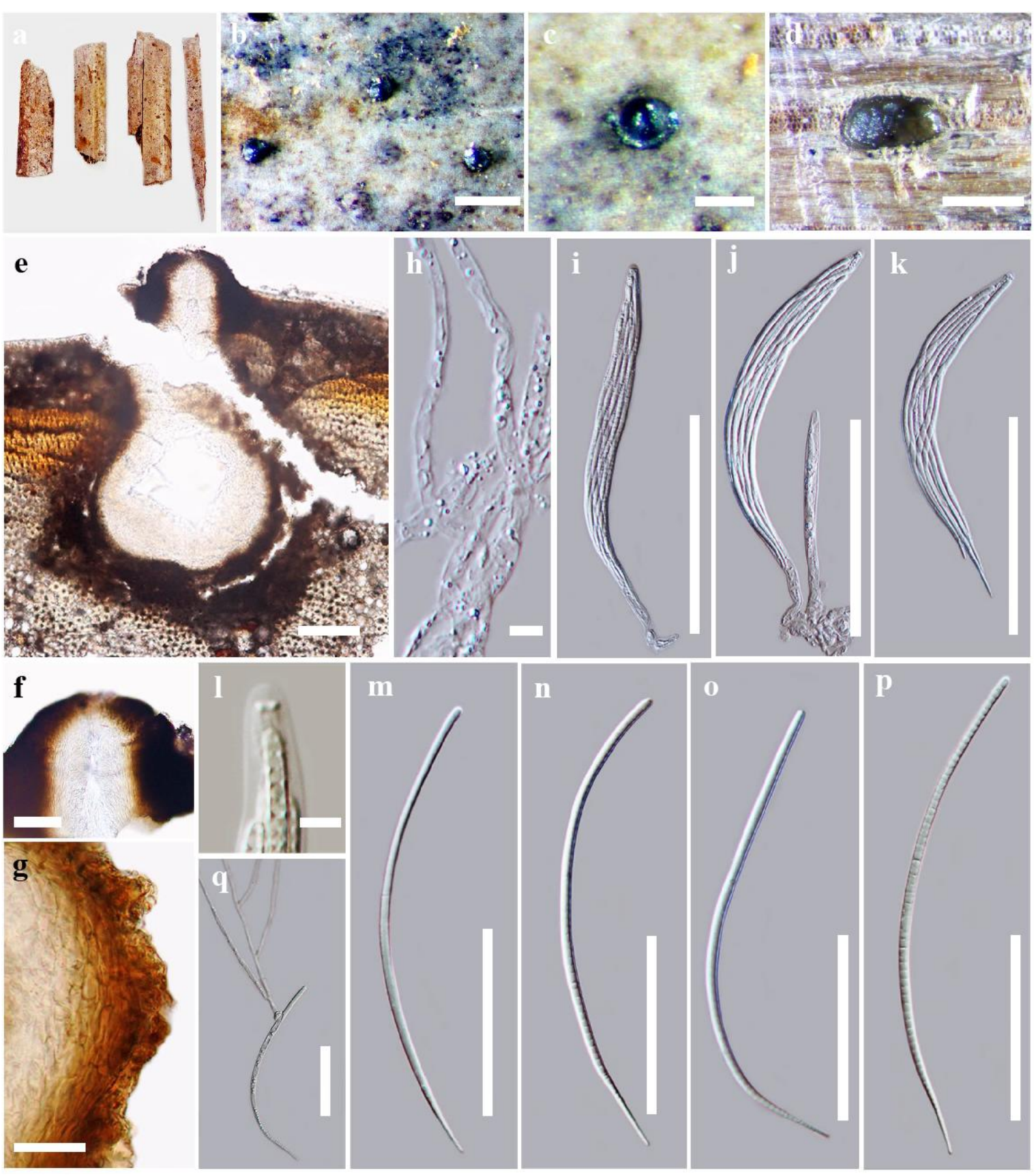

Figure 7 - Neolinocarpon rachidis (MFLU 15-0307, holotype). a Appearance of ascomata on host substrate. b, c Close up of ascomata. d Yellowish ascospore mass. e Section of ascoma. $\mathrm{f}$ Papilla. $\mathrm{g}$ Peridium. h Paraphyses. i-k Asci. $1 \mathrm{~J}$ - reaction of apical ring. $\mathrm{m}-\mathrm{p}$ Ascospores. $\mathrm{q}$ Germinated ascospore. Scale bars: $\mathrm{b}, \mathrm{d}=500 \mu \mathrm{m}, \mathrm{c}=200 \mu \mathrm{m}, \mathrm{e}, \mathrm{i}-\mathrm{k}=100 \mu \mathrm{m}, \mathrm{f}-\mathrm{g}=20 \mu \mathrm{m}, \mathrm{h}=10 \mu \mathrm{m}, 1=5$ $\mu \mathrm{m}, \mathrm{m}-\mathrm{q}=50 \mu \mathrm{m}$.

Material examined - THAILAND, Phang-Nga Province, on dead rachis of Arenga pinnata (Wurmb) Merr. (Arecaceae), 5 December 2014, Sirinapa Konta PHR06e (MFLU 15-0307, holotype); HKAS 100702, isotype; ex-type living culture, MFLUCC 15-0332).

GenBank number-SSU: MG366598

Notes - Neolinocarpon rachidis is typical of Neolinocarpon species in having deeply immersed ascomata with a shiny visible papilla and filiform, hyaline ascospores. However, it is distinct as ascospores are rounded at the apex and pointed at the base, and differing type of mucilaginous appendages (Table 1). In the phylogenetic analysis $N$. rachidis clusters with $N$. arengae (96\% ML, 1.00 PP) (Fig. 1), but the species have very different ascospores (Table 1). 


\section{Discussion}

Hyde (1992b) suggested that Linocarpon and Neolinocarpon species are similar to Lasiosphaeriaceous taxa in the apical structure of the ascus and in ascospore morphology. Hyde (1997) assigned Linocarpon and Neolinocarpon to Hyponectriaceae, Jeewon et al. (2003) also indicated Linocarpon to have relationships with Hyponectriaceae (Xylariales), while Bahl (2006) suggested Linocarpon and Neolinocarpon to have a closer relationship with Chaetosphaeriaceae and Helminthosphaeriaceae (Duong et. al 2004, Huhndorf et al. 2004). Our study confirms that these Linocarpon and Neolinocarpon should be placed in Chaetosphaeriales in a distinct family (Fig. 1).

Linocarpon (Linocarpaceae) and Leptosporella (Leptosporellaceae) species have very similar ascomata and asci and are therefore hard to distinguish. The easiest way to distinguish these genera/ families is by the ascospores. In Linocarpon the ascospores are slightly wider and have distinct, blunt, appendages at the apex, while in Leptosporella the ascospores are narrower and taper gradually towards the ends and if an appendages are present they are relatively indistinct. Neolinocarpon can be distinguished from both Linocarpon and Leptosporella as ascomata are deeply immersed and oval-globose, with a superficial, black, shiny papilla, while the ascus is sometimes provided with a refractive globose body as well as a ring. The ring with continuous structures will appear when staining with erythosin, lactofuschin and lactophenol cotton blue (Hyde 1992b). Bahl (2006) found that Linocarpon species are frequently isolated from Pandanus hosts and rarely occur on bamboo (Thongkantha et al. 2003). Fresh collections with molecular data are needed from taxa from various hosts to establish whether they have been correctly named based on modern concepts.

In this study, we introduce two new families, Leptosporellaceae and Linocarpaceae, based on phylogenetic analysis (Table 2). Both ML and BYPP analyses gave the same topologies and placed the families in Chaetosphaeriales in separate clades (Fig. 1), with Boliniales as basal. In these families, ascomata form blackened/darkened domes (Leptosporella, Linocarpon) on the host surface or are immersed with only shiny erumpent papilla showing (Neolinocarpon). Asci are unitunicate, cylindrical with J- subapical ring. Ascospores are 8-spored, filiform, hyaline, and septate or aseptate, with or without mucilaginous appendages (Fröhlich \& Hyde 2000). The nature of the ascospore appendages is important in differentiating between species (Poonyth et al. 2000). The asexual morph has rarely been observed and is Phialophora-like (Hyde 1992a). Four orders were recognized in the subclass Sordariomycetidae by Maharachchikumbura et al. $(2015,2016)$ and six well-resolved orders were reported by Hongsanan et al. (2017). The MCC tree supported the status of the families in Sordariomycetidae with stem ages between 145-216 MYA (Hongsanan et al. 2017).

Leptosporellaceae clusters as a monophyletic clade (Fig. 1) with a stable position within Chaetosphaeriales and is introduced as a novel family with a single genus Leptosporella. All species that are included in this genus have similar morphology in possessing superficial ascomata, and filiform ascospores. Linocarpaceae is introduced as a new family in Chaetosphaeriales comprising Linocarpon and Neolinocarpon. Several strains of Linocarpon and Neolinocarpon in GenBank have low quality sequence data, such as the LSU sequence data for Linocarpon pandani (type species), which are less than 800 base pairs. Thus, we used sequence data from our taxonomic novelties, plus some quality sequences in GenBank, to clarify the placement of the taxa that were previously placed in Xylariomycetidae genera incertae sedis.

\section{Acknowledgements}

Saranyaphat Boonmee would like to thank the National Research Council of Thailand (grant for microfungi on palms no. 61215320023) for supporting studies on microfungi on palms and the Mushroom Research Foundation for partly supporting this research. Sirinapa Konta is grateful to Saowaluck Tibpromma, Ausana Mapook, Mingkwan Doilom, Chayanard Phukhamsakda, Chada 
Norphunpuan, Li Junfu, Luo Zonglong, Yuanpin Xiao, Boontiya Chuankid, COE staff, Paul Kirk, and Shaun Pennycook for their valuable suggestions and helps.

\section{References}

Ariyawansa HA, Ji-Chuan Kang, Alias SA, Chukeatirote E et al. 2014 - Towards a natural classification of Dothideomycetes: The genera Dermatodothella, Dothideopsella, Grandigallia, Hysteropeltella and Gloeodiscus (Dothideomycetes incertae sedis). Phytotaxa 176, 007-017.

Arx JA von, Olivier DL. 1952 - The taxonomy of Ophiobolus graminis Sacc. Transactions of the British Mycological Society 35, 29-33.

Bahl J. 2006 - Molecular evolution of three morphologically similar families in the Xylariomycetidae (Apiosporaceae, Clypeosphaeriaceae, Hyponectriaceae). $\mathrm{PhD}$ Thesis, The University of Hong Kong.

Barr ME. 1978 - The Diaporthales in North America: with emphasis on Gnomonia and its segregates. Mycologia Memoirs 7, 1-232.

Barr ME. 1993 - Redisposition of Ellis taxa: a correction. Mycotaxon 48, 537-537.

Bhilabutra W, Lumyong S, Jeewon R, McKenzie EH et al. 2006 - Neolinocarpon penniseti sp. nov. on the grass Pennisetum purpureum (Poaceae). Cryptogamie Mycologie 27, 305-310.

Cai L, Zhang KQ, McKenzie EHC, Hyde KD. 2004 - Linocarpon bambusicola sp. nov. and Dictyochaeta curvispora sp. nov. from bamboo submerged in freshwater. Nova Hedwigia 78, 439-445.

Chardón CE. 1939 - Boletín de la Sociedad Venezolana di Ciencias Naturales 5, 335-368.

Chardón CE, Toro RA. 1934 - Mycological explorations of Venezuela. Monograph Universidad de Puerto Rico Series B 2, 1-353.

Chomnunti P, Hongsanan S, Hudson BA, Tian Q et al. 2014 - The Sooty Moulds. Fungal Diversity $66,1-36$.

Cribb AB, Cribb JW. 1955 - Marine fungi from Queensland. I. Papers of the Department of Botany University of Queensland 3, 77-81.

Dai DQ, Phookamsak R, Wijayawardene NN, Li WJ et al. 2016 - Bambusicolous fungi. Fungal Diversity 1-105.

Del Olmo-Ruiz M, Arnold AE. 2017 - Community structure of fern-affiliated endophytes in three neotropical forests. Journal of Tropical Ecology 33, 60-73.

Dulymamode R, Cannon PF, Peerally A. 1998 - Fungi from Mauritius: Linocarpon species on Pandanus. Mycological Research 102, 1331-1337.

Duong LM, Lumyong S, Hyde KD, Jeewon R. 2004 - Emarcea castanopsidicola gen. et sp. nov. from Thailand, a new xylariaceous taxon based on morphology and DNA sequences. Studies Mycology 50, 253-260.

Edward JC, Singh KP, Tripathi SC, Sinha MK et al. 1972 - Fungi associated with moribund branches of Rosa species. Sydowia 26, 266-271.

Eriksson OE. 2006 - Outline of Ascomycota - 2006. Myconet 12, 1-82.

Fröhlich J, Hyde KD. 2000 - Palm Microfungi. Fungal Diversity Research Series 3, 1-375.

Glez-Peña D, Gómez-Blanco D, Reboiro-Jato M, Fdez-Riverola F et al. 2010 - ALTER: programoriented conversion of DNA and protein alignments. Nucleic acids research 38, 14-18.

Hall T. 2004 - BioEdit. Ibis Therapeutics, Carlsbad, CA, 92008, USA.

Hansford CG. 1954 - Australian Fungi. II. New species and revisions. Proceedings of the Linnean Society of New South Wales 79, 97-141.

Hansford CG. 1957 - Australian Fungi. IV. New species and revisions (cont'd). Proceedings of the Linnean Society of New South Wales 82, 209-229.

Höhnel F von. 1909 - Fragmente zur Mykologie: VIII. Mitteilung (Nr. 354 bis 406). Sitzungsberichte der Kaiserlichen Akademie der Wissenschaften Math.-naturw. Klasse Abt. I $118,1157-1246$. 
Hongsanan S, Maharachchikumbura SSN, Hyde KD, Samarakoon MC et al. 2017 - An updated phylogeny of Sordariomycetes based on phylogenetic and molecular clock evidence. Fungal Diversity 84, 25-41.

Hsieh WH, Chen CY, Sivanesan A. 1998 - Six new ascomycetes from Taiwan. Mycological Research 102, 228-234.

Huelsenbeck JP, Ronquist F. 2001 - MRBAYES: Bayesian inference of phylogenetic trees. Bioinformatics 17, 754-755.

Huhndorf SM, Miller AN. 2011 - A molecular re-appraisal of taxa in the Sordariomycetidae and a new species of Rimaconus from New Zealand. Studies in Mycology 68, 203-210.

Huhndorf SM, Miller AN, Fernández FA. 2004 - Molecular systematics of the Sordariales: the order and the family Lasiosphaeriaceae redefined. Mycologia 96, 368-387.

Hyde KD. 1988 - The genus Linocarpon from the mangrove palm Nypa fruticans. Transactions of the Mycological Society of Japan 29, 339-350.

Hyde KD. 1989 - The genus Linocarpon from the mangrove palm Nypa fruticans. Transactions of the Mycological Society of Japan 29, 339-350.

Hyde KD. 1992a - Fungi from palms I. The genus Linocarpon, a revision. Sydowia 44, 32-54.

Hyde KD. 1992b - Fungi from decaying intertidal fronds of Nypa fruticans, including three new genera and four new species. Botanical Journal of the Linnean Society 110, 95-110.

Hyde KD. 1997 - Additions to the genus Linocarpon (ascomycetes: Hyponectriaceae). Botanical Journal of the Linnean Society 123, 109-131.

Hyde KD, Alias SA. 1999 - Linocarpon angustatum sp. nov. and Neolinocarpon nypicola sp. nov. from petioles of Nypa fruticans, and a list of fungi from aerial parts of this host. Mycoscience 40, 145-149.

Hyde KD, Cannon PF. 1999 - Fungi causing tar spots on palms. Mycological Paper 175, 1-114.

Hyde KD, Taylor JE, Fröhlich J. 1998 - Fungi from palms. XXXIV. The genus Neolinocarpon with five new species and one new combination. Fungal Diversity 1, 115-131.

Index Fungorum 2017 - http://www.indexfungorum.org/Names/Names.asp (Accessed 16 November 2017).

Jasrotia P, Green SJ, Canion A, Overholt WA et al. 2014 - Watershed-scale fungal community characterization along a $\mathrm{pH}$ gradient in a subsurface environment contaminated with uranium and nitrate. Applied and environmental microbiology 80, 1810-1820.

Jayasiri SC, Hyde KD, Ariyawansa HA, Bhat J et al. 2015 - The Faces of Fungi database: fungal names linked with morphology, phylogeny and human impacts. Fungal Diversity 74, 3-18.

Jeewon R, Hyde KD. 2016 - Establishing species boundaries and new taxa among fungi: recommendations to resolve taxonomic ambiguities. Mycosphere 7, 1669-1677.

Jeewon R, Liew EC, Hyde KD. 2003 - Molecular systematics of the Amphisphaeriaceae based on cladistic analyses of partial LSU rDNA gene sequences. Mycological Research 107, 13921402.

Jones EBG, Sakayaroj J, Suetrong S, Somrithipol S, Pang KL. 2009a - Classification of marine Ascomycota, anamorphic taxa and Basidiomycota. Fungal Diversity 35, 1-187.

Jones EB, Zuccaro A, Mitchell J, Nakagiri A et al. 2009b - Phylogenetic position of freshwater and marine Sigmoidea species: introducing a marine hyphomycete Halosigmoidea gen. nov. (Halosphaeriales). Botanica Marina 52, 349-359.

Kirk PM, Cannon PF, David JC, Stalpers JA. 2001 - Ainsworth and Bisby's dictionary of the fungi (No. Ed. 9). CABI publishing.

Katoh K, Standley K. 2013 - MAFFT Multiple Sequence Alignment Software Version 7: Improvements in Performance and Usability. Molecular Biology \& Evolution 30, 772-780.

Kumar S, Stecher G, Tamura K. 2016 - MEGA7: Molecular Evolutionary Genetics Analysis version 7.0 for bigger datasets. Molecular biology and evolution msw054.

Liu PSW. 1977 - A supplement to a host list of plant diseases in Sabah, Malaysia. Phytopathological papers 21, 1-49. 
Liu YJ, Whelen S, Hall BD. 1999 - Phylogenetic relationships among ascomycetes: evidence from an RNA polymerse II subunit. Molecular Biology and Evolution 16, 1799-1808.

Lu B, Hyde KD, Ho WH, Tsui KM et al. 2000 - Checklist of Hong Kong Fungi. Fungal Diversity Press, Hong Kong, 207 pages.

Lumbsch HT, Huhndorf SM. 2011 - Myconet Volume 14. Part One. Outline of Ascomycota2009. Part Two. Notes on Ascomycete Systematics. Nos. 4751-5113.

Maharachchikumbura SSN, Hyde KD, Jones EG, McKenzie EHC et al. 2015 - Towards a natural classification and backbone tree for Sordariomycetes. Fungal Diversity 72, 199-301.

Maharachchikumbura SSN, Hyde KD, Jones EG, McKenzie EHC et al. 2016 - Families of Sordariomycetes. Fungal Diversity 79, 1-317.

Miller AN, Huhndorf SM. 2005 - Multi-gene phylogenies indicate ascomal wall morphology is a better predictor of phylogenetic relationships than ascospore morphology in the Sordariales (Ascomycota, Fungi). Molecular phylogenetics and evolution 35, 60-75.

Nylander JAA. 2004 - MrModeltest 2.0. Program distributed by the author. Evolutionary Biology Centre, Uppsala University.

Penzig AJO, Saccardo PA. 1897 - Diagnoses fungorum novorum in insula Java collectorum. Series. I. Malpighia 11, 387-409.

Petrak F. 1952 - Über die Gattungen Gaeumannomyces v. Arx et Olivier, Halophiobolus Linder und Linocarpon Syd. Sydowia 6, 383-388.

Petrak F. 1956 - Mykologische Bemerkungen. Sydowia 10, 296-305.

Petrak F, Deighton FC. 1952 - Beiträge zur Pilzflora von Sierra Leone. Sydowia 6, 309-322.

Pinruan U, Hyde KD, Lumyong S, McKenzie EHC et al. 2007 - Occurrence of fungi on tissues of the peat swamp palm Licuala longicalycata. Fungal Diversity 25, 157-173.

Pirozynski KA. 1972 - Microfungi of Tanzania. I. Miscellaneous fungi on oil palm. Mycological Papers 129, 1-39.

Poonyth AD, Hyde KD, Wong SW, Peerally A. 2000 - Ultrastructure of asci and ascospore appendages in Linocarpon appendiculatum and L. nypae. Botanica Marina 43, 213-221.

Racovitza A. 1959 - Étude systématique et biologique des champignons bryophiles. - Mémoires du Muséum national d'histoire naturelle. Série B, Botanique 10, 1-288.

Rambaut A. 2006 - FigTree: Tree Figure Drawing Tool Version 1.4.0 2006-2012, Institute of Evolutionary Biology, University of Edinburgh.

Rehmit H. 1901 - Beiträge zur Pilzflora von Südamerika. XII. Sphaeriales. Hedwigia 40, 100-124.

Rehner SA, Buckley E. 2005 - A Beauveria phylogeny inferred from nuclear ITS and EF1- $\alpha$ sequences: evidence for cryptic diversification and links to Cordyceps teleomorphs. Mycologia 97, 84-98.

Sawada K. 1943 - Descriptive catalogue of Formosan fungi. Part IX. Report of the Department of Agriculture Government Research Institute of Formosa 86, 1-178.

Schrantz JP. 1960 - Recherches sur les pyrénomycètes de l'ordre des Diatrypales sensu Chadefaud. Bulletin de la Société Mycologique de France 76, 305-40.

Silvestro D, Michalak I. 2011 - raxmlGUI: a graphical front-end for RAxML. Organisms Diversity \& Evolution 12, 335-337.

Sivanesan A, Hsieh WH. 1989 - New species and new records of ascomycetes from Taiwan. Mycological research 93, 340-351.

Sousa da Camara, da Luz. 1939 - Agron. Lusitan 1, 47.

Spegazzini C. 1912 - Mycetes argentinenses (Series VI). Anales del Museo Nacional de Historia Natural Buenos Aires 23, 1-146.

Stamatakis A. 2006 - RAxML-VI-HPC: maximum likelihood-based phylogenetic analyses with thousands of taxa and mixed models. Bioinformatics 22, 2688-2690.

Sung GH, Sung JM, Hywel-Jones NL, Spatafora JW. 2007 - A multi-gene phylogeny of Clavicipitaceae (Ascomycota, Fungi): Identification of localized incongruence using a combinational bootstrap approach. Molecular Phylogenetics and Evolution 44, 1204-1223. 
Sydow H. 1938 - Neue oder bemerkenswerte australische Micromyceten - III. Annales Mycologici. 36, 295-313.

Sydow H, Sydow P. 1917 Beitrag zur Kenntniss der Pilzflora der Philippinen-Inseln. Annales Mycologici 15, 165-268.

Taylor JE, Hyde KD. 2003 - Microfungi of Tropical and Temperate Palms. Research Series 12, 1459.

Thongkantha S, Lumyong S, Lumyong P, Whitton SR et al. 2003 - Microfungi on the Pandanaceae: Linocarpon lammiae sp. nov., L. siamensis sp. nov. and L. suthepensis sp. nov. are described with a key to Linocarpon species from the Pandanaceae. Mycologia 95, 360367.

Turner PD. 1971 - Microorganisms associated with oil palm (Elaeis guineensis Jacq.). Phytopathological papers 14, 1-58.

Vasilyeva LN. 1993 - Pyrenomycetes of the Russian Far East. I. Gnomoniaceae. Institute of Biology \& Pedology, Russian Academy of Sciences, Far East Department, Vladivostok.

Vilgalys R, Hester M. 1990 - Rapid genetic identification and mapping of enzymatically amplified ribosomal DNA from several Cryptococcus species. Journal of Bacteriology 172, 4238-4246.

Vitoria NS, Cavalcanti MA, dos Santos CD, Pereira J et al. 2013 - Neolinocarpon attaleae sp. nov. on Attalea funifera (Arecaceae) from Brazil. Mycotaxon 123, 141-145.

Wang YZ, Hyde KD. 1999 - Hyponectria buxi with notes on the Hyponectriaceae. Fungal Diversity 3, 159-172.

Walker J. 1980 - Gaeumannomyces, Linocarpon, Ophiobolus and several other genera of scolecospored ascomycetes and Phialophora conidial state, with a note on hyphopodia. Mycotaxon 11, 1-129.

White TJ, Bruns T, Lee SJWT, Taylor JW. 1990 - Amplification and direct sequencing of fungal ribosomal RNA genes for phylogenetics. PCR protocols: a guide to methods and applications $18,315-322$.

Yanna HWH, Hyde KD. 2003 - Can ascospore ultrastructure differentiate between the genera Linocarpon and Neolinocarpon and species therein? Mycological Research 107, 1305-1313.

Zhuang WYE. 2001 - Higher Fungi of Tropical China. Mycotaxon, Ltd., Ithaca, NY, 485 pages. 